\title{
Environmental Regulation in Project-Based Industries
}

\author{
Gökçe Esenduran, ${ }^{1}$ Nicholas G. Hall, ${ }^{1}$ Zhixin Liu $^{2}$ \\ ${ }^{1}$ The Ohio State University, Fisher College of Business, 2100 Neil Ave., Columbus, OH 43210 \\ ${ }^{2}$ University of Michigan - Dearborn, College of Business, 19000 Hubbard Drive, Dearborn, MI 48126-2638
}

Received 22 March 2014; revised 3 March 2015; accepted 4 March 2015
DOI 10.1002/nav.21625
Published online in Wiley Online Library (wileyonlinelibrary.com).

\begin{abstract}
We study the environmental regulation of industrial activities that are organized as projects. Applications arise in construction, ship and aircraft building, and film making, among other industries. Relative to manufacturing, environmental regulation is different in project-based industries, due to the uniqueness and geographical diversity of projects, and a lack of product takeback programs. Because the amount of waste and pollution generated by project companies can be large, regulators need environmental policies to ensure reduction of waste and pollution. We consider a regulator who attempts to maximize social welfare. We model this problem as a bilevel nonlinear program. The upper level regulator specifies waste reduction targets, which the lower level project companies meet using waste stream reduction and remediation of pollution, while attempting to control their project costs. We find that high waste diversion targets lead to outcomes with little pollution, but excessive project costs and only modest waste stream reduction. Projects that have lower task precedence density, or that have pollutants with different environmental impacts, show larger increases in project cost and time resulting from regulation. We describe a subsidy for waste stream reduction that coordinates the system, and we estimate the value of coordination. We also describe a bonus that encourages truthful reporting by project companies, and evaluate the relative cost and effectiveness of the subsidy and the bonus. (C) 2015 Wiley Periodicals, Inc. Naval Research Logistics 62: 228-247, 2015
\end{abstract}

Keywords: environmental regulation; project management; bilevel nonlinear program; incentives

\section{INTRODUCTION}

Various economic activities, including construction, manufacturing, and transportation, are responsible for increasing environmental pollution. The resulting footprint exceeded the Earth's biocapacity by 50\% in 2007 [80]. One of the primary causes of this environmental imbalance is the amount of waste generated in industrialized nations. In response, regulators have been imposing environmental laws to ensure the diversion of waste from landfills. Although environmental regulations in manufacturing industries have been around for a long time and studied in the literature quite extensively (e.g., $[4,43])$, similar regulatory practices in project-based industries are relatively new. As we discuss below, enforcement of and compliance with environmental regulations in project-based industries present challenges that are different from those in manufacturing industries. For this reason, in this article, we focus on environmental regulation in

Correspondence to: Gökçe Esenduran (esenduran_1@ fisher.osu. edu) project-based industries from project managers', as well as from regulators', perspective.

One fifth of the world's economic activity is organized as a project [56]. As a consequence, there are several environmental regulation programs that are mandated in project-based industries. Examples of such industries include, but are not limited to, ship building, aircraft building, film making, and construction. Both ship and aircraft building projects are subject to the Resource Conservation and Recovery Act that regulates the treatment, storage and disposal of hazardous wastes and solid wastes as well as the Clean Air Act that regulates emissions limits, initial performance testing, ongoing compliance monitoring, and reporting [6, 57]. The film making industry is regulated by the Integrated Waste Management Act in California that required $50 \%$ waste reduction by 2000 [51]. In the United Kingdom, BS 8909 Standards for the film industry require waste removal, and aim at $10 \%$ reduction in carbon footprint by $2020[9,31]$. For the construction industry, CALGreen establishes green building standards within California, and mandates construction waste reduction, disposal, and recycling [12]. It requires diversion of at least 50\% of nonhazardous construction and demolition debris from 
landfills. Similarly, in the District of Columbia, the Green Building Act of 2006 requires that all public buildings meet the U.S. Green Building Council's Leadership in Energy and Environmental Design (LEED) certification standards for environmental performance [67]. Finally, the Sustainable DC plan introduces construction waste management requirements that will apply to all buildings in the district by 2032 [68]. Also, the U.K. government has identified a target of reduction in construction, demolition, and excavation waste to landfills by $50 \%$ by 2012 , relative to 2008 [37]. For the sake of brevity, in the remainder of the paper we use building construction (and related environmental regulations) as our exemplar industry. Still, our model and analysis apply readily to any environmentally sensitive industry, including those discussed above, where activities are typically organized as projects.

Under environmental regulations, identifying the most cost effective means of compliance is a significant issue for many firms operating projects. For example, compliance with CALGreen substantially increases the cost of many projects, due to the additional design work necessary to meet the requirements, as well as inspection and other onsite activities [35, 58]. In addition to cost, regulatory requirements cause an increase in project completion time. For example, time consuming onsite inspections from local and state building departments are necessary to determine compliance with CALGreen. Consequently, our paper studies the implications of such regulation for the decisions of project management companies that perform tasks which, if not remediated, pollute the environment. In particular, we identify the most cost effective means of compliance for project firms, and evaluate the increase in project cost and completion time that results from compliance.

Environmental regulation in project-based industries involves unique challenges that are different from those faced in manufacturing industries. First, project-based industries do not provide the same opportunities as manufacturing industries do for using extended producer responsibility type regulations, where the company which puts the product into the market is responsible for ensuring proper treatment of products discarded by customers, to resolve environmental concerns [50]. Second, unlike in manufacturing operations, each project is typically considered as unique [81], which makes it difficult for a regulator to design "one size fits all" environmental standards that work effectively for all projects. Another difference between manufacturing and project-based industries is a lack of repetition of tasks in the latter [2], which makes it harder to learn the effect of different responses to environmental policy. Finally, projects are often geographically diverse [59], which complicates the implementation of environmental remediation policies. For all these reasons, it is important to study environmental regulation specifically for project-based industries. In particular, we identify how different environmental regulations impact project companies' responses, which in turn affects the environmental benefit and total social welfare that result from the regulation.

The environmental economics literature compares the effectiveness of various policy tools that optimize social welfare and the amount of waste disposal. See, for example, $[54,76,10,77]$. The operations management literature also investigates various environmental policy tools and their implications, especially in manufacturing industries. Environmental regulation is accomplished through three types of programs, each of which contains various options, as we now discuss. The first type is market-based programs, which include subsidies, taxes, tax exemptions, tradeable permits, and incentives (e.g., [52, 63, 14, 41, 36]). The second type is voluntary certification programs (e.g., [73, 22]). Most closely related to our work is the third type, direct regulation programs, where a regulator states explicit, legally binding targets for remediation, such as the CALGreen Code discussed above. Direct regulation programs are widely used not only in project-based industries, but also in manufacturing industries (e.g., [82, 4, 55]). Our work focuses on direct regulation because project-based industries, including construction, are typically controlled by that type of environmental program. Our work is apparently the first that explores the impact of environmental regulation on project companies' decisions.

Project-based industries are responsible for several environmental impacts, such as various emissions, waste generation, soil erosion, noise pollution, and effects on flora and fauna. Among these environmental impacts, our work focuses on pollution and waste generation because these are commonly accepted as the creators of significant environmental problems across many industries. Regulators also typically focus on waste stream reduction and pollution remediation. For example, the Environmental Protection Agency (EPA) lists eight regulatory categories by topic as air, water, waste, pesticides, toxic substances, land and clean-up, cross-cutting issues (e.g., asbestos and lead), and emergencies [29]. Most of these topics fall within the scope of waste created by project companies.

We focus on direct regulations which impose a uniform target for companies, while allowing some flexibility in how this target is met [62]. For example, CALGreen sets the waste diversion target as $50 \%$. For project companies, there are two main options for reducing the waste to meet the targets. The first option is waste stream reduction, which reduces the waste generated by various tasks in the project [11]. The second option is direct remediation of the waste generated. In either case, waste reduction typically results in longer project time and higher cost. Therefore, it is important for project companies to identify the most cost effective means of compliance among the available alternatives.

Waste stream reduction activities decrease the amount of pollutant created by the project tasks. This contributes 
to meeting direct regulatory constraints, as the pollution reduction requirement is defined as a fraction of the amount of pollutant generated before waste stream reduction [12]. For example, leftover insulation material, which counts as construction waste, can be installed in interior wall cavities or on top of attic insulation [64]. This requires additional construction time, but helps meet waste reduction requirements. Also, additional insulation benefits the inhabitants of the building and increases consumer benefit.

We also consider two types of direct remediation. The first and most immediate type is simultaneous remediation. In our model, simultaneous remediation is performed concurrently with the task being performed by the same operators who perform the task. There are various reasons for using simultaneous remediation. For example, some hazardous waste needs to be removed immediately and, therefore, simultaneous remediation is the only option [39]. Simultaneous remediation increases task time. When it is used, no successor task can start until the remediation has been completed and the task has been certified as complete [7].

An alternative type of direct remediation is delayed remediation, which is performed at the end of the project. This remediation activity can be outsourced to external providers [11]. Many projects contain substances that require expert handling by a specialist remediation company. In this case, the remediation company has to remove materials using proper containment procedures and assess the site for other environmentally sensitive materials not identified by the project company. For example, even the simplest remediation activities such as recycling of waste components, like cardboard or wood, add to project time, if outsourced at the end of the project. This is because most remediation companies do not accept mixed loads [17], which necessitates onsite separation of construction waste [64]. As a result, even when outsourced, delayed remediation activities increase project completion time.

We model the problem faced by the regulator and the project companies as a nonlinear bilevel program to maximize social welfare, which includes project companies' cost, environmental impact, and consumer benefit. As we study the implications of the decisions of a regulator regarding regulatory parameter choices, we follow [4] and [3] by treating legislative regulation as endogenous. Then, project companies comply with the regulation either by conducting waste stream reduction activities or remediating their waste.

Two other issues that affect the decisions of the regulator and the project companies are addressed in our work. Although the upper level decision maker (regulator) may prefer certain solutions for the project companies, when those companies minimize their cost, different solutions may result. As a result, the solutions of the regulator and the project companies are not naturally coordinated. Hence, we consider how to coordinate the system using a subsidy. Also, a regulator who seeks to design optimal regulations requires information, such as the cost and amount of waste generated. For example, CALGreen requires project companies to develop a waste management plan before construction begins. The waste management plan should include the estimated amount of waste materials that will be generated, and diversion strategies for those materials [12, 13]. However, project companies do not necessarily report true information regarding the estimated amount of waste generated and the associated cost of diversion or remediation. Therefore, asymmetry of information is an issue that may significantly affect project companies' decisions as well as the success of the regulation [53]. This issue of information asymmetry in the context of sustainability has apparently not been studied in the operations management literature. Hence, we describe a bonus structure that incentivizes project companies to report their information truthfully.

Our research provides several insights for project companies and regulators. For project companies, it is important to estimate by how much project cost and time increase due to regulation, to quote to project owners. Our results show that in industries where project structures are sparse, or the regulated pollutants have different levels of environmental impact, the percentage increase in project cost is higher. Also, when the waste diversion target is small, project companies should comply by either using waste stream reduction or remediation, but not both. We also provide some insights for regulators. First, social welfare is a highly nonmonotonic function of the waste diversion targets, which underlines both the importance and the difficulty of setting optimal policy parameters. Through a computational study, we identify the implications of various suboptimal policy parameter choices and make observations to guide regulators. For example, imposing unreasonably high waste diversion targets increases the cost and completion time of projects, as expected. However, it does not result in any further waste stream reduction beyond that from the welfare maximizing waste diversion target.

Finally, we know of no other work that studies environmental regulatory constraints within the project management literature. However, there is a substantial literature about various other constraints which project companies may face. For example, resource (e.g., money, labor) constraints have been studied extensively (e.g., [24, 66, 46]). This literature aims to develop algorithms and heuristics that find optimal or near-optimal solutions for resource-constrained project management problems. We refer the reader to [34, 8] for reviews. In this article, our aim is not to develop a solution heuristic but to provide intuition to regulators and managers about the effects of environmental constraints within project-based industries. Other recent literature focuses on some practical constraints, including but not limited to, customer requirements (e.g., scope change requests [44], quality constraints 
[78], and sourcing constraints [45, 1]), and identifies several ways to address those constraints. For example, it is argued that improving integration with concurrent operations such as logistics [45], improving information flow and reducing uncertainty [78], taking proactive measures [1], and adopting a life cycle project management approach [42] would improve project performance. We contribute to this literature by identifying what type of waste diversion (i.e., remediation or reduction) would improve project performance by minimizing compliance cost under environmental regulatory constraints.

The remainder of this article is organized as follows. In Section 2, we motivate the problem studied by examining a real world example. In Section 3, we introduce our notation, model, and assumptions. In Section 4, we discuss how a project company and the regulator can identify their optimal policies. In Section 5, we provide a detailed numerical example which demonstrates that the welfare function is highly nonmonotonic. In Section 6, we first design a subsidy that aligns the objectives of the regulator and the project companies, and we study the use of a bonus that ensures truthful reporting by the project companies. In Section 7, we study the effects of various policy parameter choices. Finally, Section 8 contains a conclusion and some suggestions for future research.

\section{A REAL WORLD EXAMPLE}

To illustrate the practicality and importance of the problem of environmental regulation in project companies, we describe a construction project example that uses real data. This project is based on data from [33] and [75]. For simplicity and conciseness, we combine the tasks of the project into six subgroups, as shown in Fig. 1. Doing so defines the six tasks that are shown in Table 1. The pollutant quantities generated by each task, and the times and costs required for their remediation, appear in Tables 2 and 3, respectively $[71,38,40]$. Additional details of the example are available from the corresponding author.

In the absence of regulation, the project is completed in 36 days. In this schedule, all the tasks are critical except for task $\mathrm{D}$, which has a slack of 5 days. To provide a basis for comparing different solutions, we scale the project completion time

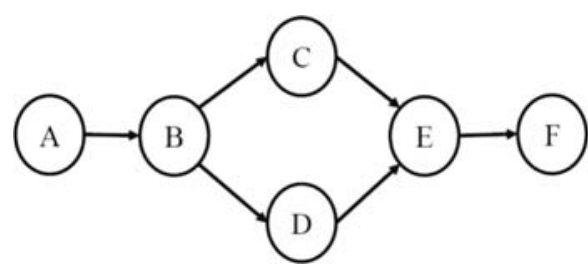

Figure 1. Construction project network structure.
Table 1. Main tasks in construction project and task durations

\begin{tabular}{llc}
\hline Task & \multicolumn{1}{c}{ Definition } & $\begin{array}{c}\text { Duration } \\
\text { (days) }\end{array}$ \\
\hline A & Earthworks & 1 \\
B & Foundation and structure & 15 \\
C & Exterior walls masonry + windows/doors fitting & 10 \\
D & Plumbing and services fixing & 5 \\
E & Interior walls & 5 \\
F & Ceiling & 5 \\
\hline
\end{tabular}

Table 2. Amount of wastes generated by main tasks.

\begin{tabular}{lrrrr}
\hline In kg's) & \multicolumn{1}{c}{ Wood } & $\begin{array}{c}\text { Concrete/ } \\
\text { ceramic }\end{array}$ & $\begin{array}{c}\text { Brick/ } \\
\text { masonry }\end{array}$ & Packaging \\
\hline Task A & 0.00 & 0.00 & 0.00 & 0.00 \\
Task B & 1279.48 & 391.14 & 0.00 & 392.73 \\
Task C & 0.00 & 132.59 & 367.93 & 811.15 \\
Task D & 0.00 & 66.29 & 0.00 & 0.00 \\
Task E & 0.00 & 0.00 & 0.00 & 1101.11 \\
Task F & 0.00 & 0.00 & 367.93 & 260.60 \\
\hline
\end{tabular}

Table 3. Time and weighted cost for remediation of pollution.

\begin{tabular}{llllc}
\hline Per kg & Wood & $\begin{array}{c}\text { Concrete/ } \\
\text { ceramic }\end{array}$ & $\begin{array}{c}\text { Brick/ } \\
\text { masonry }\end{array}$ & Packaging \\
\hline $\begin{array}{c}\text { Time of delayed reme- } \\
\text { diation (in days) }\end{array}$ & 0.00114 & 0.00091 & 0.00073 & 0.0016 \\
$\begin{array}{c}\text { Time of simultane- } \\
\text { ous remediation (in } \\
\text { days) }\end{array}$ & 0.00208 & 0.00208 & 0.00208 & N/A \\
$\begin{array}{c}\text { Cost of delayed reme- } \\
\text { diation (in \$'s) }\end{array}$ & 0.44 & 0.34 & 0.27 & 0.56 \\
$\begin{array}{c}\text { Cost of simultaneous } \\
\text { remediation (in \$'s) }\end{array}$ & 0.08 & 0.02 & 0.12 & N/A \\
\hline
\end{tabular}

into dollar units, that is, $\$ 3,600$. As increasing regulation targets are imposed on the project, additional cost is incurred. If all the four pollutants are fully remediated, then the additional project cost is approximately $\$ 2,535$, for a total of $\$ 6,135$.

Consider the remediation of concrete/ceramic waste as an example. To minimize its cost, the project company first uses simultaneous remediation for task $\mathrm{D}$, to take advantage of the slack time of that task. If additional concrete/ceramic waste diversion is required, this is accomplished using simultaneous remediation for tasks B and/or C.

To see how remediation affects the project, we consider a simple situation where the four pollutants are remediated in the same proportion. Table 4 shows how additional project cost and project delay increase with the proportion of waste remediated, as a percentage of the initial project cost of $\$ 3,600$ without remediation. Due to the existence of task slack time, project delay first increases at a lower rate, and then at a higher rate when no further slack time is available. 
Table 4. Impact of remediation on project cost and duration.

\begin{tabular}{lccccc}
\hline $\begin{array}{l}\text { Proportion of } \\
\text { waste remediated }\end{array}$ & $10(\%)$ & $20(\%)$ & $50(\%)$ & $80(\%)$ & $100(\%)$ \\
\hline $\begin{array}{c}\text { Additional project } \\
\quad \text { cost (\%) }\end{array}$ & 4.86 & 9.72 & 24.30 & 38.88 & 48.60 \\
$\begin{array}{c}\text { Delay in project } \\
\text { completion (\%) }\end{array}$ & 1.88 & 4.06 & 10.72 & 17.38 & 21.82 \\
\hline
\end{tabular}

This problem is further complicated where the project company has an additional option to divert waste, that is, to invest in waste reduction efforts to reduce pollutant quantities generated by the tasks. Also, the regulator needs to determine the proportion of each pollutant to be diverted. These issues are considered below.

\section{PRELIMINARIES}

This section describes our notation, Sections 3.1 and 3.2 formally describe the problems faced by the individual project company and the regulator, respectively. Throughout this section, we state and justify the main assumptions of our model when they are most relevant. We model the problem studied using bilevel programming [26], due to the presence of two types of decision makers, a regulator and multiple project companies.

The regulator is a higher level decision maker who sets waste reduction targets. At the lower level are $s$ project companies, each of which owns a project that is potentially affected by the regulation. Not all project companies are affected by regulation. For example, under CALGreen, the requirements apply to nonresidential additions of 2000 square feet or more. Therefore, we consider only projects that are sufficiently large to be regulated.

NOTATION: We define the following notation for problem parameters:

$$
\begin{aligned}
& s=\text { number of projects } \\
& m=\text { number of types of pollutants } \\
& n_{h}=\text { number of tasks in project } h \\
& t_{h j}=\text { deterministic task processing time for task } j \text { in } \\
& \text { project } h \\
& q_{h i j}=\text { removable amount of pollutant } i \text { generated by task } \\
& j \text { in project } h \\
& u_{h i j}=\text { time required for simultaneous remediation of one } \\
& \text { unit of pollutant } i \text { of task } j \text { in project } h \\
& u_{h i}^{\prime}=\text { time required for delayed remediation of one unit } \\
& \text { of pollutant } i \text { in project } h \\
& u_{h i j}^{\prime \prime}=\text { time required for waste reduction activity to divert } \\
& \text { one unit of pollutant } i \text { of task } j \text { in project } h
\end{aligned}
$$

$\kappa_{h i j}=$ cost required for simultaneous remediation of one unit of pollutant $i$ of task $j$ in project $h$

$\kappa_{h i}^{\prime}=$ cost required for delayed remediation of one unit of pollutant $i$ in project $h$

$\tau_{h i j}=$ cost required for reducing one squared unit of pollutant $i$ of task $j$ in project $h$

$\epsilon_{i}=$ environmental benefit from processing one unit of pollutant $i$.

Based on any practical situation, the number of pollutants, $m$, is small. Each project contains acyclic precedence relations of the form $i \rightarrow j$, indicating that task $j$ cannot start processing until the completion of task $i$ and task $i$ 's simultaneous remediation. Without loss of generality, for each project $h$, we assume that the task indexed by $n_{h}$ is a dummy task that incurs zero processing time and must be immediately preceded by any task $j<n_{h}$ satisfying $\{k \mid j \rightarrow k\}=\emptyset$. Consequently, the completion time of task $n_{h}$ is the maximum completion time of all the tasks of project $h$. However, it may be followed by delayed remediation before the project completes.

ASSUMPTION 1: We consider the problem using a project time line with respect to a schedule that has been contracted with a client.

As we consider the development of an ongoing regulatory policy that is to be applied to a variety of projects, a single period model without end effects is appropriate and sufficient. Our model considers project completion time as a measure of performance, but this time is measured against a contracted schedule with the client rather than against an abstract time horizon.

ASSUMPTION 2: We consider several project companies with a single project, who wish to minimize its cost, and we assume that all projects are completed.

This assumption implies that our model does not allow a project company to have multiple projects. This is a necessary assumption to keep the exposition clear, and focus on the main results without biasing the results with potential tradeoffs between the various options which we are studying. For example, the inclusion of learning effects or economies of scope or scale would change the tradeoff between waste remediation and reduction. We believe these are important topics that should be studied as future research problems. We also assume that all projects are completed, because to do otherwise allows the costs of canceled projects to change the tradeoffs involved in waste remediation and reduction decisions. For example, it might be the case that a project company would be more reluctant than otherwise to invest 
in waste reduction activities for a project if it was being considered for cancelation. Hence, waste remediation might be used more extensively as an alternative for this project.

\subsection{Project $h$ 's Problem}

In project $h$, we define the following decision variables:

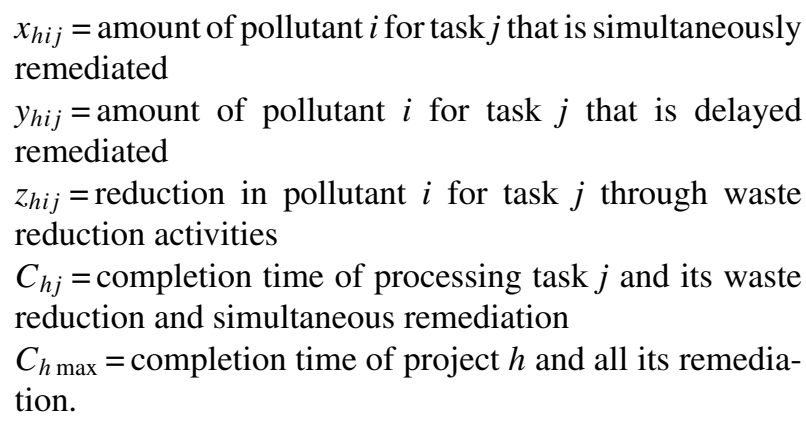

ASSUMPTION 3: The cost of reducing the amount of pollutant is convex and increasing in the amount of pollutant diverted.

We assume that the marginal cost of waste stream reduction activities, such as installing left-over insulation material, increases as waste reduction efforts become more intensive. For example, if the amount of pollutant $i$ from task $j$ of project $h$ is $q_{h i j}$, then the project company can invest in waste reduction efforts to reduce it to $q_{h i j}-z_{h i j}$, where $z_{h i j}$ is a decision variable that represents how much waste is eliminated. The cost of reducing the amount of pollutant is convex and increasing in $z_{h i j}$, that is, the amount of pollutant that is diverted from the waste stream. The assumption of increasing marginal costs for achieving higher levels of waste reduction is common in the environmental economics literature $[5,15]$. Empirical evidence also suggests that at higher levels of waste reduction the marginal abatement cost rises [15], which is consistent with convex and increasing marginal waste stream reduction costs.

Examples of waste stream reduction opportunities for construction project companies include grinding and using materials such as lumber, wood, pallets, and bricks on-site. For example, unused or damaged bricks can be ground and mixed with other materials to be used as a driveway subbase. This process reduces construction waste and thus also remediation requirements [65]. Similarly, lumber, wood, and pallets can be ground and utilized on-site for various purposes. One opportunity is using such ground wood as mulch which also provides better erosion control [65]. Another example is adjusting floor-to-ceiling heights to reduce the expected rate of plasterboard wastage, typically by $10 \%$ [79].

ASSUMPTION 4: The cost of waste remediation is linear.
Linear cost of remediation (and particularly recycling) is a common assumption in the literature (e.g., [27, 16, 4]). Furthermore, for construction waste disposal third-party remediation companies generally quote a price per pound or volume $[71,38,40,48]$. Therefore, it is reasonable to assume that the cost of remediation is linear.

We let $b_{i}$ denote the minimum proportion of pollutant $i$ that the regulator requires to be diverted through waste stream reduction or remediation. The project company solves the following optimization problem, where $\delta$ is a constant that scales $C_{h \text { max }}$ to be additive with the other costs.

$$
\begin{gathered}
\min f_{h}=\delta C_{h \max }+\sum_{i=1}^{m} \sum_{j=1}^{n_{h}}\left[\kappa_{h i j} x_{h i j}+\kappa_{h i}^{\prime} y_{h i j}+\tau_{h i j} z_{h i j}^{2}\right] \\
\text { s.t. } \quad C_{h j} \geq C_{h k}+t_{h j}+\sum_{i=1}^{m} u_{h i j} x_{h i j} \\
\quad+\sum_{i=1}^{m} u_{h i j}^{\prime \prime} z_{h i j}, \quad k \rightarrow j, \quad j, k=1, \ldots, n_{h} \\
C_{h \max } \geq C_{n_{h}}+u_{h i}^{\prime} \sum_{j=1}^{n_{h}} y_{h i j}, \quad i=1, \ldots, m \\
x_{h i j}+y_{h i j}+z_{h i j} \leq q_{h i j}, \quad i=1, \ldots, m ; j=1, \ldots, n_{h} \\
\sum_{j=1}^{n_{h}}\left(x_{h i j}+y_{h i j}+z_{h i j}\right) \geq b_{i} \sum_{j=1}^{n_{h}} q_{h i j}, \quad i=1, \ldots, m \\
x_{h i j}, y_{h i j}, z_{h i j} \geq 0, \quad i=1, \ldots, m, j=1, \ldots, n_{h} .
\end{gathered}
$$

In the objective (1), the term $C_{h \text { max }}$ is the completion time of project $h$ and all its remediation activities. The objective function minimizes the total dollar cost of the project completion time, plus the cost of remediating pollutants from the various tasks, plus the cost of waste stream reduction. Constraint (2) enforces the project's precedence requirements. The time $t_{h j}$ of task $j$ is extended by the total time spent on simultaneous remediation of that task's pollutants and the total time spent for waste stream reduction activities. Constraint (3) defines the completion time of project $h$ and all its delayed remediation. Constraint (4) requires that the total amount of the remediated and reduced pollutants cannot exceed the total amount of pollutant from each task. Constraint (5) enforces the regulator's lower limit $b_{i}$ on the proportion of type $i$ pollution that is either eliminated through waste stream reduction activities or remediated.

\subsection{Regulator's Problem}

The regulator, as an upper level decision maker, sets values for variables $b=\left(b_{1}, \ldots, b_{m}\right)$, and then the lower level 
project companies respond. There may be a technologically feasible range for $b$, so we assume $b \leq b_{\max }$, where $b_{\max }$ denotes the maximum waste diversion rate that is practically possible and $b_{\max } \leq 1$. These values apply to all projects.

ASSUMPTION 5: The regulator wishes to maximize social welfare, including several components.

The operations management literature typically models social welfare as the sum of three components, as discussed below $[49,4,53,43]$. Following the literature, we assume that the regulator's objective is to maximize a social welfare function $W$, which is the sum of company value, environmental gain, and consumer benefit. Moreover, these are the main performance measures that are impacted by the decisions we consider. We describe these three components in turn.

1. Company Value: It costs $f_{h}$ for the project company to complete project $h$. We assume the owner of project $h$ pays a fixed amount $R_{h}$, independent of $f_{h}$, to the project company. In addition, the owner pays a proportion $k_{h} \leq 1$ of the cost $f_{h}$ to the project company. This is a traditional fixed price plus cost sharing contract, with risk shared between the contractor and the project owner [60]. For example, under CALGreen, the increase in project cost due to compliance is typically reflected in the price which the building owner pays [30]. Therefore, the value of the project to the project company $h$ is $\Pi_{h}^{p} \equiv R_{h}+k_{h} f_{h}-f_{h}$, and the total value to all the project companies is $\Pi^{p}=\sum_{h=1}^{s} \Pi_{h}^{p} \equiv \sum_{h=1}^{s}\left(R_{h}+k_{h} f_{h}-f_{h}\right)$. For each project company $h$, maximizing $\Pi_{h}^{p}$ is equivalent to minimizing $f_{h}$.

2. Environmental Gain: Some environmental gain $\epsilon_{i}$ is observed from remediation or reduction of each unit of waste. See [4] and [3] for a discussion of how environmental gain or impact parameters are calculated. The linearity of total environmental benefit (respectively, damage) in the amount of waste diverted (respectively, generated) is a common assumption in the sustainable operations literature (see, for example, $[4,53,3,43]$ ) that we also adopt.

ASSUMPTION 6: The total environmental gain is linear in the amount of waste diverted.

We denote the total environmental gain from waste diversion of project $h$ by $\Pi_{h}^{e} \equiv \sum_{i=1}^{m} \epsilon_{i} \sum_{j=1}^{n_{h}}\left(x_{h i j}+\right.$ $\left.y_{h i j}+z_{h i j}\right)$. Thus, the total environmental gain from all projects is $\Pi^{e} \equiv \sum_{h=1}^{s} \Pi_{h}^{e}$.

3. Consumer Benefit: We denote the consumer benefit by $\Pi_{h}^{c}$ for project $h$. We consider three components of consumer benefit. First, a value, denoted by $V_{h}$, is gained by consumers for the completion of project $h$, for $h=1, \ldots, s$. Second, as we consider a fixed price plus cost sharing contract, the consumers need to pay $\sum_{h=1}^{s}\left(R_{h}+k_{h} f_{h}\right)$ to utilize the output of the project. Third, consumers benefit from waste stream diversion. We model these benefits as $\sum_{h=1}^{s} \sum_{i=1}^{m} \lambda_{i} \sum_{j=1}^{n_{h}}\left(x_{h i j}+y_{h i j}+z_{h i j}\right)$, where $\lambda_{i}$ is the unit increase in consumer benefit as the waste stream diversion of pollutant $i$ increases. There may be additional benefits of waste stream reduction, besides diverting waste from landfills. For example, using leftover insulation in wall cavities reduces energy bills. Indeed, governmental organizations such as the EPA emphasize the additional benefits of waste stream reduction for consumers [28]. We model the additional benefit from waste stream reduction as $\sum_{h=1}^{s} \sum_{i=1}^{m} \sum_{j=1}^{n_{h}} \lambda_{h i j}^{\prime} z_{h i j}$, where $\lambda_{h i j}^{\prime}$ is the additional unit increase in consumer benefit as the waste reduction increases. Therefore, the total consumer benefit is $\sum_{h=1}^{s}\left(V_{h}+\sum_{i=1}^{m} \lambda_{i} \sum_{j=1}^{n_{h}}\left(x_{h i j}+\right.\right.$ $\left.\left.y_{h i j}+z_{h i j}\right)+\sum_{i=1}^{m} \sum_{j=1}^{n_{h}} \lambda_{h i j}^{\prime} z_{h i j}-R_{h}-k_{h} f_{h}\right)$. However, given the assumption that all projects are completed, we omit the constant term $\sum_{h=1}^{s} V_{h}$ and thus the total consumer benefit is $\Pi^{c} \equiv$ $\sum_{h=1}^{s} \Pi_{h}^{c}=\sum_{h=1}^{s}\left(\sum_{i=1}^{m} \lambda_{i} \sum_{j=1}^{n_{h}}\left(x_{h i j}+y_{h i j}+\right.\right.$ $\left.\left.z_{h i j}\right)+\sum_{i=1}^{m} \sum_{j=1}^{n_{h}} \lambda_{h i j}^{\prime} z_{h i j}-R_{h}-k_{h} f_{h}\right)$.

From the above discussion, the regulator's problem can be written as:

$$
\begin{aligned}
& \max W= \sum_{h=1}^{s}\left(\Pi_{h}^{p}+\Pi_{h}^{e}+\Pi_{h}^{c}\right) \\
&= \sum_{h=1}^{s}\left(R_{h}+k_{h} f_{h}-f_{h}\right) \\
&+\sum_{h=1}^{s} \sum_{i=1}^{m}\left(\epsilon_{i}+\lambda_{i}\right) \sum_{j=1}^{n_{h}}\left(x_{h i j}+y_{h i j}+z_{h i j}\right)+ \\
& \sum_{h=1}^{s}\left(\sum_{i=1}^{m} \sum_{j=1}^{n_{h}} \lambda_{h i j}^{\prime} z_{h i j}-R_{h}-k_{h} f_{h}\right) \\
&=-\sum_{h=1}^{s} f_{h}+\sum_{h=1}^{s} \sum_{i=1}^{m}\left(\epsilon_{i}+\lambda_{i}\right) \sum_{j=1}^{n_{h}}\left(x_{h i j}+y_{h i j}\right. \\
&\left.+z_{h i j}\right)+\sum_{h=1}^{s} \sum_{i=1}^{m} \sum_{j=1}^{n_{h}} \lambda_{h i j}^{\prime} z_{h i j} \\
& \text { s.t. } \quad 0 \leq b_{i} \leq b_{\max }, \quad i=1, \ldots, m
\end{aligned}
$$

where $f_{h}$ is the minimum cost of project $h$, and $x_{h i j}, y_{h i j}$, and $z_{h i j}$ are given by an optimal solution of project $h$ 's problem (1)-(6), for any given $b=\left(b_{1}, \ldots, b_{m}\right)$. The objective 
$W$ represents the social welfare function. The first term in (8) is the project company's cost, the second term is the environmental and consumer benefit from waste diversion and the third term is the additional consumer benefit from waste stream reduction.

ASSUMPTION 7: At different points in our work, we assume perfect information or asymmetric information.

Most of the operations management literature on sustainability (e.g., [4, 63, 69, 53]) assumes perfect information, that is, the regulator knows all the relevant information about the manufacturer's costs and resources. This assumption includes the regulator knowing the unit waste diversion costs of all the projects. This assumption is supported by [70], who propose a scheme to approximate the unit remediation costs of the other parties. We follow this assumption for our initial analysis, but modify it in Section 6.

Finally, note that although we focus on the environmental impact of waste, our model is general enough to be applied to other environmental impacts faced in project-based industries, for example, dust emission or noise pollution. For example, for the environmental impact under consideration, if reduction is costly but not time consuming, then this would be a special case of our model where the parameters $u_{h i j}, u_{h i}^{\prime}$, and $u_{h i j}^{\prime \prime}$ are set to zero.

\section{UNCOORDINATED SOLUTIONS}

We discuss how each project company and the regulator can optimize their decision problems.

\subsection{Project $h$ 's Solution}

We consider the problem faced by project company $h$ in the uncoordinated case. First, we show that a project company has no incentive to invest more in waste reduction activities, or to remediate more pollutant, than is required by the regulator.

LEMMA 1: An optimal solution to a project company's problem satisfies (5) with equality.

PROOF: The minimization objective of the project company is an increasing function of each $x_{h i j}, y_{h i j}$, and $z_{h i j}$ variable.

\subsection{Regulator's Solution}

We provide a discussion of how the regulator optimizes its objective in the uncoordinated case. The regulator can maximize $W$ over $b_{i}, x_{h i j}, y_{h i j}, z_{h i j}$, and $C_{h j}$, subject to Constraints
(2)-(6) and (9), where Constraint (5) is in equality form, else the $b$ vector found in an optimal solution can simply be $\mathbf{0}$, and does not define the proportion of each pollutant to process. Doing so optimizes the regulator's objective, however the values of $x_{h i j}, y_{h i j}, z_{h i j}$, and $C_{h j}$ obtained do not necessarily optimize the project company's problem for the chosen $b_{i}$ values. Hence, it may not be a "true solution" where the project company makes the decisions that the regulator expects. In this case, the regulator's solution is not optimal.

For given $b=\left(b_{1}, \ldots, b_{m}\right)$, the minimum cost $f_{h}$ of project $h$ is unique, but there can be multiple optimal solutions for $x_{h i j}, y_{h i j}, z_{h i j}$. The existence of multiple optimal $x_{h i j}, y_{h i j}, z_{h i j}$ solutions complicates the regulator's decisions about $b=\left(b_{1}, \ldots, b_{m}\right)$. We assume that, given minimization of its own cost, a project company always maximizes the social welfare. We provide an algorithm to solve the regulator's problem under this assumption. Before presenting the algorithm, we need to introduce the Karush-Kuhn-Tucker (KKT) optimality conditions of the project company's quadratic program. To this end, we define $\alpha_{h k j}, \beta_{h i}, \gamma_{h i j} \geq 0$ as dual variables for Constraints (2), (3), and (4), respectively. From Lemma 1, Constraint (5) always holds as an equality, hence we define $\eta_{h i}$ as a dual variable, which is not necessarily nonnegative, for Constraint (5). The KKT conditions for the minimization of the objective $f_{h}$, subject to Constraints (2)-(5), are

$$
\begin{aligned}
& \alpha_{h k j}\left(C_{h k}+t_{h j}+\sum_{i=1}^{m} u_{h i j} x_{h i j}+\sum_{i=1}^{m} u_{h i j}^{\prime \prime} z_{h i j}-C_{h j}\right)=0, \\
& k \rightarrow j, j, k=1, \ldots, n_{h}, \\
& \beta_{h i}\left(C_{n_{h}}+u_{h i}^{\prime} \sum_{j=1}^{n_{h}} y_{h i j}-C_{h \max }\right)=0, i=1, \ldots, m,
\end{aligned}
$$

$$
\begin{aligned}
& \gamma_{h i j}\left(x_{h i j}+y_{h i j}+z_{h i j}-q_{h i j}\right)=0 \\
& \quad i=1, \ldots, m ; j=1, \ldots, n_{h}, \\
& \nabla\left(f_{h}+\sum_{k \rightarrow j} \alpha_{h k j}\left(C_{h k}+t_{h j}+\sum_{i=1}^{m} u_{h i j} x_{h i j}\right.\right. \\
& \left.\quad+\sum_{i=1}^{m} u_{h i j}^{\prime \prime} z_{h i j}-C_{h j}\right) \\
& \quad+\sum_{i} \beta_{h i}\left(C_{n_{h}}+u_{h i}^{\prime} \sum_{j=1}^{n_{h}} y_{h i j}-C_{h \max }\right) \\
& +\sum_{i, j} \gamma_{h i j}\left(x_{h i j}+y_{h i j}+z_{h i j}-q_{h i j}\right) \\
& \left.\quad+\sum_{i=1}^{m} \eta_{h i}\left(b_{i} \sum_{j=1}^{n_{h}} q_{h i j}-\sum_{j=1}^{n_{h}}\left(x_{h i j}+y_{h i j}+z_{h i j}\right)\right)\right)=0
\end{aligned}
$$




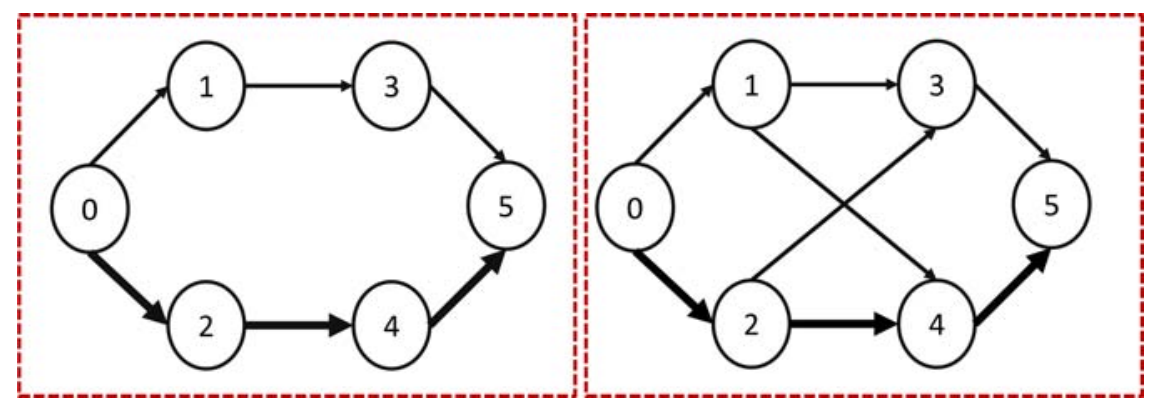

Figure 2. Project network structure for Example 1. [Color figure can be viewed in the online issue, which is available at wileyonlinelibrary.com.]

where Constraint (13) specifies the first order condition of the Lagrangian function over the variables $x_{h i j}, y_{h i j}, z_{h i j}$, $C_{h j}$, and $C_{h \max }$.

The regulator's problem can be solved as a bilevel program, using the following algorithm.

ALGORITHM 1: Allow the regulator to maximize $W$ over variables $b_{i}, x_{h i j}, y_{h i j}, z_{h i j}$, and $C_{h j}$, subject to constraints (2)-(6), (9), and (10)-(13). This is an optimistic bilevel nonlinear program [19], where in the case of multiple optimal solutions for a project company, the company chooses one with maximum social welfare.

The bilevel nonlinear program in our paper is equivalent to a leader-follower game, where the regulator is the leader and the project companies are followers. In the next section, we provide a detailed numerical example to demonstrate that the welfare function is highly nonmonotonic, and therefore, finding closed form analytical solutions is not tractable.

\section{UNCOORDINATED SOLUTIONS: A NUMERICAL EXAMPLE}

To have a better understanding of the optimal solution of the project companies and the regulator when their decisions are uncoordinated, we provide a detailed example. Consider two projects with activity-on-node network structures, as shown in Fig. 2. For simplicity, we focus on an example with one pollutant, and hence for this section we omit the subscript denoting the pollutant. Notation of a vector is indicated by bold. For example, $\boldsymbol{t}_{\mathbf{1}}=\left(t_{11}, \ldots, t_{1 n_{h}}\right)$. The critical paths for $b=0$ are shown using bold lines in Fig. 2. For the pollutant under consideration, $\epsilon=1.2$ and $\lambda=0.5$.

EXAMPLE 1: For Project 1, the task times are given as $\boldsymbol{t}_{\mathbf{1}}=(3,3,4,1,5,2)$, whereas the remediation times are $\boldsymbol{u}_{\mathbf{1}}=$ $(1.2,1.5,1,1.7,0.2,1)$ and $u_{1}^{\prime}=0.5$. Time required for waste reduction activities are $\boldsymbol{u}_{1}^{\prime \prime}=(0.5,0.8,0.3,0.5,0.1,0.3)$. The cost of reducing one squared unit of pollutant is $\boldsymbol{\tau}_{\mathbf{1}}=(3,5,4,2,2,3)$. The remediation costs are $\boldsymbol{\kappa}_{\mathbf{1}}=$ $(0.6,4,1.2,1,0.7,1.2)$ and $\kappa_{1}^{\prime}=1.5$ for simultaneous and delayed remediation, respectively. Finally, the amount of pollutant from each task is $\boldsymbol{q}_{\mathbf{1}}=(2.5,4,5,3,5,4)$, and the additional increase in consumer benefit as the waste reduction increases is $\lambda_{1}^{\prime}=(16,26.5,21,15.5,7,10.5)$. For Project 2, the problem parameters are as follows: $\boldsymbol{t}_{\mathbf{2}}=$ $(2,1,4,2,7,2), \boldsymbol{u}_{\mathbf{2}}=(1,2,2,6,3,1), u_{2}^{\prime}=1.7, \boldsymbol{u}_{2}^{\prime \prime}=$ $(0.3,0.5,0.5,0.4,0.3,0.2), \boldsymbol{\tau}_{2}=(3,5,4.5,2,1,2.5), \boldsymbol{\kappa}_{\mathbf{2}}=$ $(1,2,1,1.5,0.5,1), \kappa_{2}^{\prime}=0.3, \boldsymbol{q}_{2}=(2.5,6,6,1.5,5,4)$, and $\lambda_{2}^{\prime}=(11.5,21,17.5,21.5,10.5,16)$. Finally, let $\delta=1$.

We solve the project companies' problem for $b \in$ $\{0,0.01,0.02, \ldots, 1\}$, and graph the total welfare and its components in Fig. 3a. From the figure, we observe that the total project cost and environmental gain are monotonically increasing functions of $b$, whereas additional consumer benefit is a monotone and weakly increasing function of $b$. As the total welfare is defined as the sum of consumer benefit and environmental gain minus project cost, the total welfare function is a nonmonotone, mostly concave, function of $b$. This feature of the objective function's structure illustrates the difficulty of finding optimal solutions as well as closed form analytical solutions.

In this example, we identify the optimum value $b^{*}=0.48$ that maximizes the total welfare. Recall that consumer benefit is a function of the weighted sum of waste reduction of the project tasks (8). The optimal level of waste reduction, and thus the nonmonotonic shape of the total welfare function are determined by the strategies of the project companies for different waste diversion targets. From analyzing the project companies' response to increasing levels of $b$, we have several observations. First, when $b$ is small, each project company complies with regulation by making small changes in the waste stream reduction level, without performing any remediation. As the cost of decreasing the pollutant level is convex and increasing in $z$, it is cheaper to make such design changes for small values of $z$. The project company stops investing in waste stream reduction activities when the 

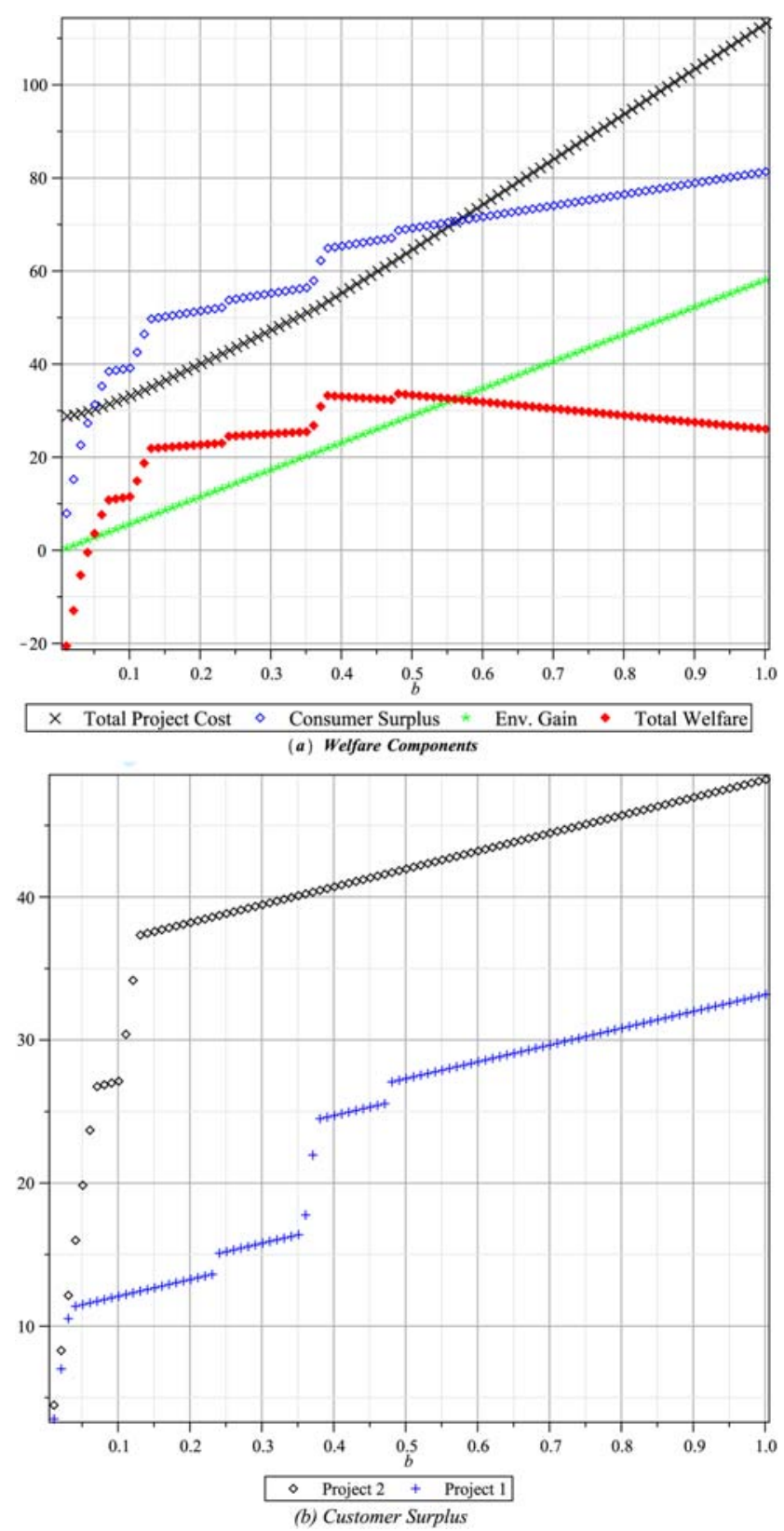

Figure 3. Solution of Example 1: (a) change in total welfare components as $b$ increases; (b) change in consumer benefit for each project as $b$ increases. [Color figure can be viewed in the online issue, which is available at wileyonlinelibrary.com.]

related convex cost is higher than the cost of remediation for the cheapest available task. At higher levels of $b$, the project company begins using remediation to comply with the regulation. Intuition suggests that the cheapest means of compliance is through simultaneous remediation for the tasks that are not on the critical path, however, this is not necessarily the case. Although remediating the waste from a task that is on the critical path increases the project completion time, the project company may choose to do so when the corresponding cost of simultaneous remediation is sufficiently low.

Once simultaneous remediation starts, as $b$ increases, no further investment is made in waste reduction activities until the remediation opportunity is fully exploited. Suppose for example that, at any $b$ value, it is currently optimal to use simultaneous remediation. Then, the project company continues using simultaneous remediation to comply with more stringent regulation, until either (i) all the available slack time for the particular task is used up for remediation and thus the task becomes critical, or (ii) all the waste generated from this task is remediated, even though there is still some slack time available for the task. Observe that the optimal strategy alternates between waste stream reduction and waste remediation. This is because of the tradeoff between the convex cost of reducing waste and the linear cost of remediation. Any further increase in $b$ is satisfied through investing in waste reduction activities or remediation, but not both. A more extensive numerical study suggests that the observations in this paragraph and the previous one are typical.

We also identify some insights for the regulator. Sometimes, remediating all the waste is infeasible, due to technological constraints. That is, there may be a technologically feasible range for $b$. In that case, the regulator needs to select $b$ carefully, as the total welfare function is not monotonic. If $b^{*}$ is not in the range of feasible $b$ values, then choosing the closest feasible $b$ value does not necessarily give the maximum possible welfare. As discussed above, the nonmonotonicity of the total welfare function is due to the consumer benefit component. We observe nonmonotonic behavior in the ranges of $b$ where all the projects comply through simultaneous or delayed remediation and no project increases its investment in waste reduction activities (see Fig. 3). This is less likely to happen when the number of projects is large and the projects have significantly different cost and/or network structures, because then there is typically at least one project that complies by increasing its investment in waste reduction activities. Therefore, the less homogeneous project structures are, the closer to monotonic is the social welfare function.

\section{COORDINATED SOLUTIONS}

In this section, we consider two approaches to improve on an uncoordinated solution, by bringing it closer to a globally optimal solution. In Section 6.1, we consider the use of a subsidy that aligns the objectives of the regulator and the project companies, assuming that the project companies provide true information about their data. In Section 6.2, we study the use of a bonus that encourages truthful reporting by the project companies. 


\subsection{Coordination by Subsidy}

We show how the regulator can coordinate the system to maximize social welfare. We design a subsidy to be paid to each project company that encourages the company's investment in waste reduction activities, simplifies the regulator's selection of $b$, and coordinates the system. Let $f_{h}^{0}$ be the cost of project $h$ without regulation. We define the following subsidy $D_{h}$ to be paid to each company $h$ :

$$
\begin{aligned}
D_{h}= & \min \left\{\left(1-k_{h}\right)\left(f_{h}-f_{h}^{0}\right), \sum_{i=1}^{m} \sum_{j=1}^{n_{h}} \lambda_{h i j}^{\prime} z_{h i j}\right. \\
& \left.-k_{h}\left(f_{h}-f_{h}^{0}\right)\right\} .
\end{aligned}
$$

By definition, the subsidy either fully compensates the extra cost incurred by project company $h$ due to regulation, or pays project company $h$ back for all the consumer benefit generated due to its investment in waste reduction activities minus the additional cost incurred by the project owner due to regulation, whichever is less. Hence, the project company cannot gain more from the subsidy than its increase in cost due to regulation. The subsidy coordinates the decisions of the regulator and the project companies, as we now show.

THEOREM 1: With a subsidy defined by (14), if the regulator optimizes its objective subject to Constraints (2)-(6) and (9), then the optimal values of $x_{h i j}, y_{h i j}, z_{h i j}, C_{h j}$, and $C_{h \max }$ obtained directly optimize project company $h$ 's problem for the chosen vector $b$.

PROOF: First, consider the case where the subsidy takes value $\left(1-k_{h}\right)\left(f_{h}-f_{h}^{0}\right)$. In this situation, the project company incurs no additional cost compared to the case without regulation. Hence, deviating from the solution $x_{h i j}, y_{h i j}, z_{h i j}$, $C_{h j}$, and $C_{h \text { max }}$ that optimizes social welfare cannot generate higher value for the project company.

Second, consider the case where the subsidy takes value $\sum_{i=1}^{m} \sum_{j=1}^{n_{h}} \lambda_{h i j}^{\prime} z_{h i j}-k_{h}\left(f_{h}-f_{h}^{0}\right)$. In such a situation, the project company's total value becomes

$$
\begin{aligned}
\Pi_{h}^{p^{\prime}} & =\Pi_{h}^{p}+D_{h} \\
& =R_{h}+k_{h} f_{h}-f_{h}+\sum_{i=1}^{m} \sum_{j=1}^{n_{h}} \lambda_{h i j}^{\prime} z_{h i j}-k_{h}\left(f_{h}-f_{h}^{0}\right) .
\end{aligned}
$$

As $R_{h}$ and $f_{h}^{0}$ are constants, maximizing (16) is equivalent to maximizing

$$
-f_{h}+\sum_{i=1}^{m} \sum_{j=1}^{n_{h}} \lambda_{h i j}^{\prime} z_{h i j} .
$$

Whereas, the social welfare $W^{\prime}$ under the subsidy payment is

$$
\begin{aligned}
W^{\prime}= & \sum_{h=1}^{s}\left(\Pi_{h}^{p^{\prime}}+\Pi_{h}^{e}+\Pi_{h}^{c}-D_{h}\right) \\
= & -\sum_{h=1}^{p} f_{h}+\sum_{h=1}^{s} \sum_{i=1}^{m}\left(\epsilon_{i}+\lambda_{i}\right) \sum_{j=1}^{n_{h}}\left(x_{h i j}+y_{h i j}+z_{h i j}\right) \\
& +\sum_{h=1}^{s} \sum_{i=1}^{m} \sum_{j=1}^{n_{h}} \lambda_{h i j}^{\prime} z_{h i j} \\
= & -\sum_{h=1}^{s} f_{h}+\sum_{h=1}^{s} \sum_{i=1}^{m} \sum_{j=1}^{n_{h}} \lambda_{h i j}^{\prime} z_{h i j} \\
& +\sum_{h=1}^{s} \sum_{i=1}^{m}\left(\epsilon_{i}+\lambda_{i}\right) b_{i} \sum_{j=1}^{n_{h}} q_{h i j}
\end{aligned}
$$

where the last equality follows from Lemma 1 and the last term is independent of the project company's decision variables.

Therefore, using the subsidy $\sum_{i=1}^{m} \sum_{j=1}^{n_{h}} \lambda_{h i j}^{\prime} z_{h i j}-k_{h}\left(f_{h}-\right.$ $\left.f_{h}^{0}\right)$, the values of $x_{h i j}, y_{h i j}, z_{h i j}, C_{h j}$, and $C_{h \text { max }}$ obtained by the regulator to optimize (19) also optimize project company $h$ 's total value (17) for the chosen vector $b$.

The use of the subsidy $D_{h}$ simplifies the decision about $b$ by the regulator. With the subsidy, as the regulator solves a single stage problem, the maximum social welfare is achieved, subject to truthful reporting by the project companies about their data. Also, this subsidy structure shows that the regulator may be able to coordinate the system by paying project companies less than full compensation for the cost of their compliance. This is because they also benefit from coordination. Further, the subsidy encourages investment in waste reduction activities by the project companies. An important issue is how this subsidy affects the value of the project companies, the consumer benefit, and the environmental gain. In Section 7 , we describe a computational study to investigate this question and estimate the value of coordination.

Finally, we would like to note that subsidies are widely criticized because they may create a burden on government revenues and may end up effectively being paid by taxpayers. Still, government subsidies have historically been used as an environmental policy tool [72]. As governments' budgets for subsidies shrink, subsidies may come from nongovernmental entities. An alternative is relying on subsidized-interest loans (as, for example, in Germany).

\subsection{Encouraging Truthful Reporting}

The analysis in Section 6.1 assumes that the regulator has perfect knowledge of the project companies' time and 
cost parameters. The cost and time for remediation follow industry standards and can be quoted from third party waste management companies. However, project companies have information regarding their costs of compliance, which are typically unknown to regulators [61]. For example, investment in waste reduction activities incurs company-specific costs, and a company may view this information as confidential. In this section, we describe an incentive for a project company to report its cost of investment in waste reduction activities to the regulator truthfully. Although rigorous enforcement of pollution regulations is an alternative, in project-based industries it is not easy for a regulator to know pollution details at the individual task level, and project companies know that, which increases their temptation to cheat.

Kwerel [47] studies the issue of misreporting remediation costs under two pollution control schemes; tradeable permits and effluent taxes. He proposes a hybrid scheme including both tradeable permits and effluent taxes, and shows that, under this scheme, firms have an incentive to report their remediation costs truthfully. Dasgupta et al. [23] identify some limitations of the method proposed by [47], and describe a two-round communication scheme. They discuss schemes that induce firms to announce their true cost functions, following the Vickrey-Clarke-Groves (VCG) public choice mechanism of $[74,18,32]$. The VCG mechanism uses a publicly announced bonus scheme to incentivize selfinterested parties to reveal true information to a central regulator who makes decisions relevant to all the parties. We study a similar setting, and design a bonus scheme which the regulator can use to incentivize the project companies to reveal their true parameters.

We first introduce some notation. Let $\theta=\left\{\theta_{1}, \ldots, \theta_{s}\right\}$ and $\hat{\theta}=\left\{\hat{\theta}_{1}, \ldots, \hat{\theta}_{s}\right\}$ denote the reported and true parameters of the project companies, respectively. Here, $\theta_{h}$ can include all the parameters ${ }^{1}$ which project company $h$ uses for its project scheduling, investment in waste reduction activities, and remediation decisions, for example, $t_{h j}, q_{h i j}$, precedence relations, and $\tau_{h i j}$. Thus, $\theta_{h}$ and $\hat{\theta}_{h}$ denote the sets of reported and true parameters of project company $h$, respectively; and $\theta_{\backslash h}=\left\{\theta_{1}, \ldots, \theta_{h-1}, \theta_{h+1}, \ldots, \theta_{s}\right\}$ denotes the reported parameters of companies other than $h$. For notational convenience, we denote $\theta$ by $\left(\theta_{h}, \theta_{\backslash h}\right)$, and $\left\{\theta_{1}, \ldots, \theta_{h-1}, \hat{\theta}_{h}, \theta_{h+1}, \ldots, \theta_{s}\right\}$ by $\left(\hat{\theta}_{h}, \theta_{\backslash h}\right)$.

For a given regulation vector $b$, let $\Pi_{h}^{p}\left(b, \theta_{h}\right)$ denote the company value of project $h$ with parameters $\theta_{h}$; let $\Pi^{e}\left(b, \theta_{h}, \theta_{\backslash h}\right)$ and $\Pi^{c}\left(b, \theta_{h}, \theta_{\backslash h}\right)$ denote the total environmental gain and total consumer benefit from all the project

\footnotetext{
${ }^{1}$ As aforementioned, certain time and cost parameters (e.g., $u_{h i j}$, $\left.u_{h i}^{\prime}, \kappa_{h i j}, \kappa_{h i}^{\prime}\right)$ can be estimated from publicly available information if available. Otherwise, $\theta_{h}$ can be used to model these parameters.
}

companies with parameters $\left(\theta_{h}, \theta_{\backslash h}\right)$, respectively; and let $W^{*}\left(\theta_{\backslash h}\right)$ denote the total social welfare from all the project companies except for company $h$ with parameters $\theta_{\backslash h}$, in an optimal coordinated solution.

Let $B_{h}\left(b^{*}\left(\theta_{h}, \theta_{h}\right), \theta_{h}, \theta_{\backslash h}\right)$ be a bonus paid to project company $h$ under reported parameters $\left(\theta_{h}, \theta_{\backslash h}\right)$, where $b^{*}\left(\theta_{h}, \theta_{\backslash h}\right)$ is the regulation vector in an optimal coordinated solution for the project companies with parameters $\left(\theta_{h}, \theta_{\backslash h}\right)$. For truthful reporting to be a dominant strategy for project company $h$, it is sufficient that, for any $\theta_{h}$ and $\theta_{\backslash h}$,

$$
\begin{aligned}
& \Pi_{h}^{p}\left(b^{*}\left(\theta_{h}, \theta_{\backslash h}\right), \hat{\theta}_{h}\right)+B\left(b^{*}\left(\theta_{h}, \theta_{\backslash h}\right), \theta_{h}, \theta_{\backslash h}\right) \\
& \quad \leq \Pi_{h}^{p}\left(b^{*}\left(\hat{\theta}_{h}, \theta_{\backslash h}\right), \hat{\theta}_{h}\right)+B\left(b^{*}\left(\hat{\theta}_{h}, \theta_{\backslash h}\right), \hat{\theta}_{h}, \theta_{\backslash h}\right) .
\end{aligned}
$$

That is, no matter how the other project companies report their parameters, truthfully reporting its parameters maximizes project company $h$ 's total value.

REMARK 1: Based on the truth inducing mechanism described by [23], the following bonus for each project company $h$ is truth inducing:

$$
\begin{aligned}
B\left(b^{*}\left(\theta_{h}, \theta_{\backslash h}\right), \theta_{h}, \theta_{\backslash h}\right)= & \Pi^{e}\left(b^{*}\left(\theta_{h}, \theta_{\backslash h}\right), \theta_{h}, \theta_{\backslash h}\right) \\
& +\Pi^{c}\left(b^{*}\left(\theta_{h}, \theta_{\backslash h}\right), \theta_{h}, \theta_{\backslash h}\right) \\
+ & \sum_{k \neq h} \Pi_{k}^{p}\left(b^{*}\left(\theta_{h}, \theta_{\backslash h}\right), \theta_{k}\right)-W^{*}\left(\theta_{\backslash h}\right) .
\end{aligned}
$$

We note that the fourth term, $-W^{*}\left(\theta_{\backslash h}\right)$, of the bonus is independent of the reported parameters of project $h$. The first three terms of the bonus plus the company value of project $h$ is exactly the total social welfare obtained from project company $h$ 's perspective. Observing that the regulator maximizes the total social welfare with reported parameters $\left(\theta_{h}, \theta_{\backslash h}\right)$, reporting its true parameters maximizes project $h$ 's total value, including the company value and the bonus.

The bonus defined by (20) is the marginal contribution of project $h$ to the total social welfare under regulation, minus the company's value of project $h$. Using this bonus, the social welfare is maximized when each company makes decisions that maximize its total value. Under this bonus scheme, a company misreporting its information receives less bonus than when reporting true information, and hence the bonus can be regarded as a penalty for misreporting in a general sense. However, regulatory enforcement with arbitrary penalty for misreporting can be difficult to implement, due to the difficulty for a regulator to recognize misreported information and to differentiate intentional and unintentional misreporting.

The maximized social welfare is always nonnegative, as the social welfare is 0 when $b_{i}=0$ for every $i$. However, the bonus is not necessarily positive. In general, if a project company is much less efficient at reducing pollutants compared 
with other companies, then its marginal contribution to the social welfare can be negative, as can its bonus defined by (20). It is worth noting that the bonus (20) remains truth inducing if the term $-W^{*}\left(\theta_{\backslash h}\right)$ is replaced by any function that is independent of the reported parameters of project company $h$.

There are some limitations to this bonus scheme. First, the regulated pollutant system incentivized by the bonus is not budget balanced. For a system to be budget balanced, the total value received by all the parties in the system should be no more than the value generated by the system. In our problem, to be budget balanced, the total bonus should be no more than the sum of the environmental benefit and the consumer benefit, which does not always hold. Second, the bonus scheme suffers from a lack of transparency, that is, the bonus amount remains unknown until all the firms have reported their information. This makes the bonus scheme unappealing to its potential participants. Third, there may be unintentional inaccuracies in the values that the project company reports, due, for example, to miscalculation or poor estimation. Our bonus structure does not resolve this issue. Furthermore, in practice firms may have other concerns about revealing their true information, which could make implementation of this bonus scheme difficult. For example, firms may want to hide the information from their competitors or even their customers. The last three limitations are true for all such bonus schemes. Hence, despite their truth inducing property and the fact that such bonus schemes are studied in the literature, they are not widely used in practice. For other incentive mechanisms that are designed for environmental protection, see $[20,21]$.

\section{COMPUTATIONAL STUDY}

This section provides computational results that illustrate the solutions obtained by the regulator and the project companies. There are two main goals of this section. First, we design a computational study to investigate the effects of the regulator deviating from an optimal decision in Section 7.1. Second, in Section 7.2, we study the effectiveness and cost of the subsidy described in Section 6.1 and the bonus described in Section 6.2.

\subsection{Uncoordinated Solutions}

The waste diversion targets chosen by the regulator affect the project companies' behavior, which in turn affects the total social welfare. In practice, multiple different policies are often considered in the regulatory design process. We propose four policies, each of which represents a different approach by the regulator to determine the regulation vector $b$ with $b_{\max }=\mathbf{1}$.
1. High Accuracy Policy (HAP): Enumeratively find a vector $b$ that maximizes social welfare, where each $b_{i}$ is a multiple of 0.01 . This is an approximation for the optimal solution that can be obtained using Algorithm 1.

2. Low Accuracy Policy (LAP): Enumeratively find a vector $b$ that maximizes social welfare, where each $b_{i}$ is a multiple of 0.1 . This policy represents a situation when the regulator sets targets imprecisely.

3. Greedy Policy (GP): Use the vector $b=\mathbf{1}$, that is, $b_{i}=1$ for every $i$. This policy represents a situation where the regulator maximizes the environmental benefit.

4. Stepwise Policy (SP): For $i=1, \ldots, m$, find the value $b_{i}$ as a multiple of 0.01 that maximizes social welfare, given $b_{1}, \ldots, b_{i-1}$ values already found and $b_{i+1}, \ldots, b_{m}$ values all equal to 0 . This policy represents a situation where the regulator updates the current policy by including new pollutants one at a time.

In practice, HAP is a reasonable policy, as it is quite precise and setting $b_{i}$ even more precisely is difficult to justify. We study all these policies for a wide variety of parameter settings, to obtain robust conclusions. Our data set is created by generating project instances using RanGen [25]. For a given number of tasks, RanGen generates task processing times from the integer uniform distribution between 1 and 10 , that is, $t_{h j} \sim U I[1,10]$, for all $h, j$. Let $d$ denote the density of the precedence graph, that is the ratio of the number of precedence relations generated, including transitive relations, to the theoretical maximum number of precedence relations. We use RanGen to generate project instances with $n_{h} \in\{10,20\}$ and $d \in\{0.2,0.5\}$. Then, for each instance generated, we generate pollutant and remediation parameters as follows:

1. $q_{h i j} \sim U\left[0, t_{h j}\right], \quad h=1, \ldots, s, i=1, \ldots, m$, $j=1, \ldots, n_{h}$

2. $\tau_{h i j} \sim U[0,1], h=1, \ldots, s, i=1, \ldots, m$, $j=1, \ldots, n_{h}$

3. $u_{h i j}, \kappa_{h i j} \sim U[0,1], \quad h=1, \ldots, s, i=1, \ldots, m$, $j=1, \ldots, n_{h}$

4. $u_{h i}^{\prime}, \kappa_{h i}^{\prime} \sim U[0,0.4], \quad h=1, \ldots, s, i=1, \ldots, m$, $j=1, \ldots, n_{h}$.

Thus, in our setting, on average a type of pollutant of a task requires simultaneous and delayed remediation times that are $1 / 4$ and $1 / 10$ of the task processing time, respectively. We then generate $\lambda_{h i j}^{\prime} \sim U[0, .4], \forall h, i, j$. To separate the effects of waste reduction and remediation, we let $u_{h i j}^{\prime \prime}=0, \forall h, i, j$ and $\lambda_{i}=0, \forall i$. For each project $h$, we let the fixed project revenue $R_{h}$ equal the project cost when there is no waste 
Table 5. Distribution of social welfare for different policies.

\begin{tabular}{|c|c|c|c|c|c|c|c|c|c|c|c|c|}
\hline & \multicolumn{3}{|c|}{ HAP } & \multicolumn{3}{|c|}{ LAP } & \multicolumn{3}{|c|}{ GP } & \multicolumn{3}{|c|}{ SP } \\
\hline & $\Pi^{p}$ & $\Pi^{e}$ & $\Pi^{c}$ & $\Pi^{p}$ & $\Pi^{e}$ & $\Pi^{c}$ & $\Pi^{p}$ & $\Pi^{e}$ & $\Pi^{c}$ & $\Pi^{p}$ & $\Pi^{e}$ & $\Pi^{c}$ \\
\hline$n_{h}=10$ & -16.69 & 24.48 & 9.76 & -17.37 & 24.98 & 9.74 & -91.47 & 69.33 & 11.91 & -16.46 & 24.28 & 9.69 \\
\hline$n_{h}=20$ & -32.89 & 51.24 & 20.21 & -32.68 & 50.98 & 19.91 & -172.02 & 135.32 & 24.11 & -32.37 & 50.72 & 20.14 \\
\hline$d=0.2$ & -24.81 & 38.27 & 15.09 & -25.13 & 38.46 & 14.94 & -130.91 & 102.39 & 18.19 & -24.34 & 37.80 & 15.03 \\
\hline$d=0.5$ & -24.76 & 37.44 & 14.88 & -24.91 & 37.51 & 14.70 & -132.58 & 102.26 & 17.82 & -24.48 & 37.19 & 14.79 \\
\hline$m=1$ & -12.82 & 19.48 & 8.98 & -13.53 & 19.99 & 9.00 & -90.58 & 61.35 & 11.79 & -12.82 & 19.48 & 8.98 \\
\hline$m=2, \epsilon E$ & -27.03 & 40.96 & 18.42 & -26.84 & 40.71 & 18.10 & -153.52 & 122.86 & 21.30 & -26.50 & 40.46 & 18.30 \\
\hline$m=2, \epsilon N$ & -34.51 & 53.14 & 17.55 & -34.70 & 53.24 & 17.37 & -151.14 & 122.76 & 20.94 & -33.91 & 52.55 & 17.45 \\
\hline Overall & -24.79 & 37.86 & 14.98 & -25.02 & 37.98 & 14.82 & -131.74 & 102.33 & 18.01 & -24.41 & 37.50 & 14.91 \\
\hline
\end{tabular}

diversion requirement, that is, when $b_{i}=0$ for every pollutant $i$. We also let the variable project revenue parameter $k_{h}=0$. For simplicity, we let $\delta=1$. Under these parameter settings, the project company value is scaled to be nonpositive, but the environmental gain and the consumer benefit are both nonnegative. The purpose for choosing these parameter settings is to ensure that the project company value, the environmental gain, and the consumer benefit consist only of components that are affected by decisions about waste remediation and reduction.

The problem instances we consider contain $s \in\{5,10\}$ projects. We consider three scenarios for $m$ and $\epsilon$. First, we let $m=1$ and $\epsilon_{1}=0.2$. Second, we let $m=2$ and $\epsilon_{1}=\epsilon_{2}=0.2$. Third, we let $m=2, \epsilon_{1}=0.1$ and $\epsilon_{2}=0.3$. Thus, for parameters $n_{h} \in\{10,20\}, d \in\{0.2,0.5\}, s \in\{5,10\}$, and the three scenarios for $m$ and $\epsilon$, we have $2 \times 2 \times 2 \times 3=24$ combinations for problem settings, for each of which we generate 10 problem instances, for a total of 240 instances.

To understand the implications of each policy, we address the following questions:

i. In a regulated environment, how is the social welfare allocated among the stakeholders?

ii. By how much does social welfare decrease as the regulator moves away from the best solution?

iii. By how much do the project cost and time increase as a result of regulation?

iv. How do companies divide their compliance activities between waste remediation and waste reduction?

The first two questions consider the regulator's decisions. We identify how the total welfare changes and who pays for the regulation cost. The last two questions consider the project company's decisions. We study the compliance cost and the cost minimizing compliance methods, under regulation. Table 5 summarizes how the distribution of the total social welfare is affected by the parameters $n_{h}, d, m$, and $\epsilon$. We observe that the environmental gains of Policy GP come at much higher cost for the project companies. Recall that
Table 6. Percentage loss of social welfare, relative to HAP, for different policies.

\begin{tabular}{lccccc}
\hline & $\mathrm{LAP}_{0.05}$ & $\mathrm{LAP}_{0.1}$ & $\mathrm{LAP}_{0.2}$ & $\mathrm{GP}$ & $\mathrm{SP}$ \\
\hline$s=5$ & 0.47 & 1.16 & 3.96 & 159.01 & 0.25 \\
$s=10$ & 0.35 & 1.02 & 3.72 & 163.75 & 0.13 \\
$n_{h}=10$ & 0.42 & 1.20 & 4.25 & 176.81 & 0.19 \\
$n_{h}=20$ & 0.40 & 0.97 & 3.43 & 145.95 & 0.19 \\
$d=0.2$ & 0.37 & 1.05 & 3.98 & 160.66 & 0.17 \\
$d=0.5$ & 0.45 & 1.12 & 3.70 & 162.10 & 0.21 \\
$m=1$ & 0.48 & 1.25 & 5.54 & 214.95 & 0.00 \\
$m=2, \epsilon E$ & 0.40 & 1.20 & 3.99 & 140.50 & 0.28 \\
$m=2, \epsilon N$ & 0.35 & 0.81 & 1.99 & 128.69 & 0.29 \\
Overall & 0.41 & 1.09 & 3.84 & 161.38 & 0.19 \\
\hline
\end{tabular}

Policy GP represents the regulator imposing high waste diversion targets. In this case, the results in Table 5 imply that high waste reduction targets lead to unbalanced outcomes with no pollution, but with excessive project costs. Table 5 also shows that the allocation of the environmental gains increases, while the allocation of consumer benefit decreases, with pollutant heterogeneity, as in the case of $m=2, \epsilon N$.

Next, we consider how the percentage loss of social welfare generated by the other policies relative to that by HAP is affected by the parameters $s, n_{h}, d, m$, and $\epsilon$. Observing that Policy LAP naturally causes welfare loss due to its use of relatively large increments in enumerating each $b_{i}$ value, we now extend Policy LAP to enumerate each $b_{i}$ as a multiple of $0.05,0.1$, and 0.2 , denoted by $\mathrm{LAP}_{0.05}, \mathrm{LAP}_{0.1}$, and $\mathrm{LAP}_{0.2}$, respectively. The results are summarized in Table 6. Evidently, the welfare loss increases with the degree of inaccuracy Policy LAP uses. Interestingly, Policy SP provides a loss of social welfare that is only about one fifth that of Policy $\mathrm{LAP}_{0.1}$. Therefore, it should be possible to add regulatory requirements for additional pollutants without changing the existing requirements. Further, our results show that Policy SP performs substantially better as the number of projects increases.

As expected, compliance with regulations such as CALGreen increases project completion time and cost [30]. Note 
Table 7. Percentage increase in project cost and time due to regulation under different policies

\begin{tabular}{|c|c|c|c|c|c|c|c|c|}
\hline & \multicolumn{2}{|c|}{ HAP } & \multicolumn{2}{|c|}{ LAP } & \multicolumn{2}{|c|}{ GP } & \multicolumn{2}{|c|}{ SP } \\
\hline & $f_{h}$ & $C_{h \max }$ & $f_{h}$ & $C_{h \max }$ & $f_{h}$ & $C_{h \max }$ & $f_{h}$ & $C_{h \max }$ \\
\hline$s=5$ & 13.93 & 2.32 & 14.11 & 2.39 & 71.43 & 22.77 & 13.66 & 2.24 \\
\hline$s=10$ & 13.25 & 1.95 & 13.40 & 2.03 & 71.88 & 22.88 & 13.07 & 1.92 \\
\hline$n_{h}=10$ & 10.70 & 1.78 & 11.14 & 1.94 & 59.69 & 19.88 & 10.53 & 1.75 \\
\hline$n_{h}=20$ & 16.48 & 2.49 & 16.37 & 2.48 & 83.62 & 25.78 & 16.19 & 2.40 \\
\hline$d=0.2$ & 16.13 & 2.46 & 16.38 & 2.55 & 84.73 & 26.77 & 15.80 & 2.37 \\
\hline$d=0.5$ & 11.05 & 1.81 & 11.13 & 1.86 & 58.58 & 18.89 & 10.93 & 1.78 \\
\hline$m=1$ & 6.99 & 0.72 & 7.41 & 0.84 & 48.61 & 18.00 & 6.99 & 0.72 \\
\hline$m=2, \epsilon E$ & 14.65 & 1.88 & 14.60 & 1.93 & 83.89 & 25.42 & 14.32 & 1.81 \\
\hline$m=2, \epsilon N$ & 19.13 & 3.81 & 19.26 & 3.85 & 82.46 & 25.06 & 18.78 & 3.70 \\
\hline Overall & 13.59 & 2.14 & 13.76 & 2.21 & 71.65 & 22.83 & 13.36 & 2.08 \\
\hline
\end{tabular}

that we assume that once $b$ is given, the project companies must comply with the regulation requirement. Symmetrically with Policy GP where $b=\mathbf{1}$, a firm greedy policy implies that $b=\mathbf{0}$, that is, no regulation. We study the magnitude of increases over project completion time and cost relative to the case with $b=\mathbf{0}$. Table 7 shows the increment in the project cost $\left(f_{h}\right)$ and in the completion time of a project including its waste diversion $\left(C_{h \max }\right)$, relative to a situation with no regulation, for the four policies. Observe that, in the absence of environmental regulation, the project cost is equal to the project completion time. The results in Table 7 show that all the policies except GP mitigate the incremental costs of environmental regulation rather effectively, typically to less than $14 \%$. Moreover, project completion times typically increase less than $3 \%$.

A surprising observation from Table 7 is that the incremental cost and time from regulation are significantly less when the number of precedence relations is greater. One explanation for this result is that, when $d$ is high, the initial project cost is higher and thus the percentage increase is lower. A second explanation follows from the tradeoff between the different welfare components. When projects have more precedence relations, it is more difficult and costlier to comply with regulations, because there is less slack time between the activities that can be used for remediation. Therefore, a higher waste diversion target results in higher project cost, and lower total welfare. For this reason, the welfare maximizing $b_{i}$ value and the percentage increase in project costs are smaller when projects are denser.

Finally, we observe that a larger increase in project cost and project completion time occurs where the two pollutants have different levels of environmental benefit when diverted. This outcome results from the fact that the project cost function is convex and increasing in $b$. We consider the case where the pollutants have the same environmental benefit from diversion $\left(\epsilon E: \epsilon_{1}=\epsilon_{2}=0.2\right)$, and where pollutants have different environmental benefits from diversion $\left(\epsilon N: \epsilon_{1}=0.1\right.$ and $\left.\epsilon_{2}=0.3\right)$. When $\epsilon_{i}=0.3$, the corresponding optimal $b_{i}$ is higher, and meeting the higher $b_{i}$ value requires more waste diversion, which is costlier and requires more time. Differences between the results for Policies HAP, LAP, and SP are not significant.

It is important to understand how project companies respond to regulation. Table 8 summarizes the percentages by which waste is reduced by simultaneous remediation, delayed remediation, and waste stream reduction activities, using the four policies. The results show that, under Policy GP, project companies predominantly use delayed remediation. This is because slack times are filled by simultaneous remediation, and the cost of waste reduction activities increases in a convex way. The other three policies achieve remediation by about 13,6 , and $14 \%$ on average using delayed remediation, simultaneous remediation, and waste reduction, respectively. These results are quite stable across the parameter ranges studied, except that the prevalence of delayed remediation increases with the number of precedence relations, the number of pollutants, and the pollutant heterogeneity. The results for Policy GP show that unreasonably high waste diversion requirements do not encourage more waste reduction than welfare maximizing waste diversion requirements do. When faced with stringent waste reduction requirements, project companies use delayed remediation instead of simultaneous remediation or waste stream reduction. Hence, our results imply that imposing high waste diversion targets may not be completely successful in terms of incentivizing waste stream reduction activities.

\subsection{Coordinated Solutions}

We next consider coordinated solutions, where the regulator selects a vector $b$ and pays a subsidy $D_{h}$, as defined by (14), to each project company $h$. As a result, project companies invest in waste reduction activities and make remediation decisions that maximize the total social welfare.

We evaluate the distribution of the social welfare, the subsidy, and the increase in total social welfare from the coordinated policy relative to that of Policy HAP, the best uncoordinated solution with direct regulation, and summarize the results in Table 9. Compared with the distribution of the social welfare obtained by Policy HAP, the project cost and the consumer benefit both increase significantly, but the environmental benefit increases by only a small amount. The subsidy is slightly smaller than the consumer benefit. After receiving the subsidy, the project company's costs are significantly reduced, as shown in column $\Pi_{\text {subs }}^{p}$. Compared instance by instance, coordinated solutions offer on average $19 \%$ more value in social welfare than Policy HAP in the uncoordinated case. The percentage gain in social welfare is stable across the parameters considered. 
Table 8. Percentage waste diversion approaches for different policies: simultaneous remediation (Smt), delayed remediation, and waste reduction (Red)

\begin{tabular}{|c|c|c|c|c|c|c|c|c|c|c|c|c|}
\hline & \multicolumn{3}{|c|}{ HAP } & \multicolumn{3}{|c|}{ LAP } & \multicolumn{3}{|c|}{ GP } & \multicolumn{3}{|c|}{ SP } \\
\hline & Smt & Delayed & Red & Smt & Delayed & Red & Smt & Delayed & Red & Smt & Delayed & Red \\
\hline$s=5$ & 12.67 & 6.70 & 14.54 & 12.90 & 6.91 & 14.43 & 20.03 & 62.50 & 17.48 & 12.61 & 6.43 & 14.49 \\
\hline$s=10$ & 13.06 & 5.80 & 14.32 & 13.22 & 6.04 & 14.23 & 20.86 & 61.41 & 17.73 & 12.97 & 5.69 & 14.25 \\
\hline$n_{h}=10$ & 11.40 & 6.32 & 14.21 & 11.67 & 6.73 & 14.16 & 18.84 & 63.67 & 17.49 & 11.28 & 6.15 & 14.13 \\
\hline$n_{h}=20$ & 14.33 & 6.18 & 14.65 & 14.46 & 6.22 & 14.49 & 22.04 & 60.24 & 17.72 & 14.30 & 5.97 & 14.61 \\
\hline$d=0.2$ & 13.74 & 5.69 & 14.48 & 14.05 & 5.96 & 14.44 & 22.20 & 59.96 & 17.84 & 13.66 & 5.48 & 14.44 \\
\hline$d=0.5$ & 11.99 & 6.80 & 14.37 & 12.07 & 6.99 & 14.21 & 18.68 & 63.95 & 17.37 & 11.92 & 6.64 & 14.30 \\
\hline$m=1$ & 13.24 & 3.96 & 14.46 & 13.72 & 4.27 & 14.51 & 23.21 & 58.05 & 18.74 & 13.24 & 3.96 & 14.46 \\
\hline$m=2, \epsilon E$ & 12.74 & 5.14 & 14.70 & 12.76 & 5.29 & 14.47 & 19.26 & 63.56 & 17.17 & 12.58 & 4.97 & 14.62 \\
\hline$m=2, \epsilon N$ & 12.62 & 9.64 & 14.12 & 12.71 & 9.86 & 14.01 & 18.85 & 64.25 & 16.90 & 12.56 & 9.26 & 14.03 \\
\hline Overall & 12.87 & 6.25 & 14.43 & 13.06 & 6.47 & 14.33 & 20.44 & 61.95 & 17.60 & 12.79 & 6.06 & 14.37 \\
\hline
\end{tabular}

Table 9. Distribution of social welfare for solutions coordinated by subsidy

\begin{tabular}{lccccccc}
\hline & & & & & & & Gain \\
& $\Pi^{p}$ & $\Pi^{e}$ & $\Pi^{c}$ & Subsidy & $\Pi_{\text {subs }}^{p}$ & Gain & $(\%)$ \\
\hline$s=5$ & -20.86 & 26.35 & 16.69 & 16.56 & -4.30 & 3.43 & 18.98 \\
$s=10$ & -40.42 & 51.42 & 33.37 & 33.23 & -7.19 & 7.03 & 19.09 \\
$n_{h}=10$ & -20.72 & 25.43 & 16.18 & 16.14 & -4.58 & 3.34 & 19.64 \\
$n_{h}=20$ & -40.55 & 52.34 & 33.88 & 33.64 & -6.91 & 7.11 & 18.43 \\
$d=0.2$ & -30.73 & 39.25 & 25.45 & 25.29 & -5.44 & 5.41 & 19.35 \\
$d=0.5$ & -30.54 & 38.52 & 24.61 & 24.49 & -6.05 & 5.04 & 18.72 \\
$m=1$ & -16.19 & 20.06 & 14.72 & 14.55 & -1.65 & 2.95 & 19.48 \\
$m=2, \epsilon E$ & -33.73 & 41.88 & 30.50 & 30.26 & -3.47 & 6.31 & 19.54 \\
$m=2, \epsilon N$ & -41.99 & 54.71 & 29.87 & 29.87 & -12.12 & 6.42 & 18.09 \\
Overall & -30.64 & 38.89 & 25.03 & 24.89 & -5.75 & 5.23 & 19.04 \\
\hline
\end{tabular}

Next, we study how the bonus in (20) and the project company value are affected by different factors. We compare the cost and effectiveness of the bonus defined by (20) and the subsidy defined by (14). We note that the bonus achieves the same social welfare as the subsidy for every instance, as they both coordinate the system. Our results are summarized in Table 10. Columns Bonus and $\Pi_{\text {bonus }}^{p}$ show the bonus and the company value with the bonus paid, respectively. Columns $\% \frac{\text { Bonus }}{\Pi_{\text {bonus }}^{e}+\Pi_{\text {bonus }}^{c}}$ and $\% \frac{\text { Bonus }}{\text { Subsidy }}$ show the bonus as a percentage of the environmental benefit plus consumer benefit, and of the subsidy, respectively. With the bonus, the project companies gain extra value by remediating pollutants, especially when the pollutant heterogeneity is high. The bonus needed is on average no more than $80 \%$ of the total of the environmental benefit and consumer benefit generated by the company, and thus typically does not create a budget deficit. Finally, the bonus is on average about twice the subsidy. However, we do observe cases where the total bonus paid to the project companies is negative. We find that the bonus needed is substantially higher where the two pollutants have different levels of environmental benefit when remediated. This is because higher pollutant heterogeneity leads to larger optimal values of $b_{i}$,
Table 10. Effectiveness of the bonus

\begin{tabular}{lcccc}
\hline & Bonus & $\Pi_{\text {bonus }}^{p}$ & $\% \frac{\text { Bonus }}{\Pi_{\text {bonus }}^{e}+\Pi_{\text {bonus }}^{c}}$ & $\% \frac{\text { Bonus }}{\text { Subsidy }}$ \\
\hline$s=5$ & 32.10 & 11.25 & 72.29 & 188.78 \\
$s=10$ & 62.50 & 22.09 & 73.14 & 188.04 \\
$n_{h}=10$ & 31.28 & 10.56 & 72.52 & 188.15 \\
$n_{h}=20$ & 63.33 & 22.78 & 72.91 & 188.68 \\
$d=0.2$ & 46.30 & 15.57 & 69.93 & 180.03 \\
$d=0.5$ & 48.30 & 17.76 & 75.50 & 196.80 \\
$m=1$ & 24.44 & 8.25 & 70.10 & 171.88 \\
$m=2, \epsilon E$ & 50.71 & 16.98 & 69.43 & 166.20 \\
$m=2, \epsilon N$ & 66.77 & 24.78 & 78.62 & 227.16 \\
Overall & 47.30 & 16.67 & 72.72 & 188.41 \\
\hline
\end{tabular}

and thus a higher marginal contribution to social welfare. This observation does not apply to the subsidy in Table 9 . The reason is that the subsidy is bounded above by the consumer benefit (14), and as the consumer benefit is insensitive to pollutant heterogeneity, so too is the subsidy.

The distribution of total social welfare among company value, environmental gain, and consumer benefit is scaled by the weighting parameters $\epsilon_{i}, \lambda_{i}$, and $\lambda_{h i j}^{\prime}$. In the studies reported above, we use a fixed scheme in generating these parameters. We now study how these parameters affect the distribution of total social welfare in a coordinated solution. Specifically, we generate each of the three parameters from uniform intervals [0,0.1], [0.1,0.2], [0.2,0.3], [0.3,0.4], and $[0.4,0.5]$. Hence, there are $5 \times 5 \times 5=125$ combinations of these parameters. Further, we still vary the parameters $s, n_{h}, d$, and $m$ as in our earlier studies, and generate 10 instances for each parameter combination, for a total of $125 \times 16 \times 10=20,000$ random instances. The results are summarized in Table 11. First, company value strongly decreases with $\epsilon_{i}$ and $\lambda_{i}$ following a similar pattern, and decreases slightly with $\lambda_{h i j}^{\prime}$. This is because the parameters $\epsilon_{i}$ and $\lambda_{i}$ play the same role in encouraging both direct remediation and waste stream reduction, whereas the parameter $\lambda_{h i j}^{\prime}$ 
Table 11. Distribution of social welfare by different weights.

\begin{tabular}{lrrr}
\hline & \multicolumn{1}{c}{$\Pi^{p}$} & \multicolumn{1}{c}{$\Pi^{e}$} & $\Pi^{c}$ \\
\hline$\epsilon_{i} \sim U[0,0.1]$ & -69.75 & 14.97 & 122.92 \\
$\epsilon_{i} \sim U[0.1,0.2]$ & -92.18 & 53.71 & 138.23 \\
$\epsilon_{i} \sim U[0.2,0.3]$ & -111.65 & 103.54 & 146.81 \\
$\epsilon_{i} \sim U[0.3,0.4]$ & -124.56 & 157.97 & 149.82 \\
$\epsilon_{i} \sim U[0.4,0.5]$ & -128.70 & 206.87 & 150.57 \\
$\lambda_{i} \sim U[0,0.1]$ & -69.46 & 90.60 & 47.20 \\
$\lambda_{i} \sim U[0.1,0.2]$ & -92.66 & 105.02 & 88.15 \\
$\lambda_{i} \sim U[0.2,0.3]$ & -111.54 & 111.65 & 138.91 \\
$\lambda_{i} \sim U[0.3,0.4]$ & -125.07 & 114.78 & 192.73 \\
$\lambda_{i} \sim U[0.4,0.5]$ & -128.10 & 114.99 & 241.36 \\
$\lambda_{h i j}^{\prime} \sim U[0,0.1]$ & -97.13 & 106.70 & 111.08 \\
$\lambda_{h i j}^{\prime} \sim U[0.1,0.2]$ & -99.82 & 106.79 & 122.93 \\
$\lambda_{h i j}^{\prime} \sim U[0.2,0.3]$ & -104.21 & 107.54 & 138.93 \\
$\lambda_{h i j}^{\prime} \sim U[0.3,0.4]$ & -109.58 & 108.08 & 157.27 \\
$\lambda_{h i j}^{\prime} \sim U[0.4,0.5]$ & -116.09 & 107.94 & 178.13 \\
Overall & -105.37 & 107.41 & 141.67 \\
\hline
\end{tabular}

only affects waste stream reduction [see (8)]. Second, the environmental gain increases strongly with $\epsilon_{i}$ and slightly with $\lambda_{i}$, and is not affected by $\lambda_{h i j}^{\prime}$. Third, consumer benefit increases slightly with $\epsilon_{i}$, strongly with $\lambda_{i}$, and moderately with $\lambda_{h i j}^{\prime}$. The last two findings occur because the parameter $\epsilon_{i}$ directly affects environmental gain and the parameter $\lambda_{i}$ directly affects consumer benefit, in both direct remediation and waste stream reduction; whereas, the parameter $\lambda_{\text {hij }}^{\prime}$ only affects consumer benefit in waste stream reduction.

Finally, we study the impacts of unintentional information inaccuracies, as mentioned in Section 6.2. We focus on information inaccuracy regarding the removable amount of pollutant $q_{h i j}$. Let the reported value be denoted by $\hat{q}_{h i j}=r q_{h i j}$, where $r$ represents the degree of information inaccuracy. We consider three scenarios for $r$ : (1) random errors where $r \sim U[0.9,1.1]$; (2) underestimates where $r \sim U[0.9,1]$; and (3) overestimates where $r \sim U[1,1.1]$. We find that the three scenarios of misreporting all reduce the total social welfare by an amount between 2 and 4\%, compared with accurate reporting. For project cost, environmental gain and consumer benefit, overreporting under scenario 3 has the largest impact. On average it reduces total project cost by $5.2 \%$, reduces environmental gain by $4.61 \%$, and reduces consumer benefit by $1.49 \%$. The impacts of random errors and underreporting are less evident and do not follow a consistent pattern. In summary, information inaccuracies have a negative impact on total social welfare as expected, and overreporting of pollutant quantity typically benefits project companies at the expense of the environment and consumers.

\section{CONCLUDING REMARKS}

The construction industry is among the major sources of waste and pollution in industrialized nations. Moreover, commercial activities within the construction industry are typically organized as projects, as they are in ship and aircraft building, and in film making. This organizational structure has significant implications for the ways in which companies respond to environmental regulation. These implications motivate us to study the environmental regulation of project companies. We consider the decisions of a regulator, and the decisions made in response by project companies. The regulator's problem of maximizing social welfare is modeled as a bilevel nonlinear program. We describe a subsidy for investment in waste reduction activities that coordinates the decisions of the regulator and the project companies. We also describe a bonus that ensures truthful reporting by project companies about their remediation costs and other data that the regulator does not directly observe. Finally, we investigate the implications of the regulator deviating from an optimal decision, for (a) total social welfare, (b) average project cost and time, and (c) project companies' waste diversion policy choices.

Our work provides several implications for project companies operating in industries that are environmentally regulated. First, we identify the optimal strategy for complying with regulations, and find that increases in waste diversion targets are satisfied through remediation or waste reduction, but not both. As they need to quote to project owners, project companies have a significant concern about by how much regulation will increase project cost and completion time. Our results suggest that, in industries where project structures have higher density, the percentage increase in project cost due to regulation is lower than where project structures are sparse. Further, if the regulated pollutants have different levels of environmental impact, larger increases in project cost and completion time occur.

We also provide several implications for regulators. For example, it is important for regulators to understand the structure of projects in their industry. When projects have similar network structures, the total welfare function is typically a nonmonotonic function of the waste diversion target, which makes it harder to estimate the effect of regulation on social welfare. The results of our computational study emphasize the importance of identifying welfare maximizing regulatory parameters. Imposing stringent waste diversion targets typically results in unbalanced outcomes with no pollution, but with excessive project costs; it also fails to encourage waste stream reduction. Finally, a positive result is that it should be possible to add regulatory requirements for more pollutants without changing the existing requirements. This results in only a small sacrifice in the total social welfare, relative to resetting all waste diversion targets, which could be disruptive to companies and result in poor public relations.

Several interesting issues remain open for further research. First, a computationally efficient algorithm can be developed for the regulator's bilevel quadratic program. Second, a more 
general problem that allows for task expediting or "crashing" can be considered. Crashing can be used to compensate for the project lengthening effects of remediation. Third, project resource constraints can be considered in a more general model. Fourth, it should be possible to develop a more general model in which each project company owns several projects, which would allow for the modeling of learning effects and economies of scope or scale. Finally, the design of environmental regulations that are customized, either for individual project companies or for sectors of a project-based industry, should be studied. We hope that our work will encourage further research on these important issues.

\section{ACKNOWLEDGMENTS}

We thank the Associate Editor and an anonymous reviewer for their constructive comments, which have substantially improved the quality of this work. We are also grateful to Prof. L.X. Lu and Prof. B. Toktay for their helpful feedback.

\section{REFERENCES}

[1] T. Ala-Risku and M. Kärkkäinen, Material delivery problems in construction projects: A possible solution, Int J Prod Econ 104 (2006), 19-29.

[2] R. Ambriz and J. White, Dynamic scheduling with microsoft project 2010: The book by and for professionals, J. Ross Publishing and International Institute for Learning, Inc., Florida, 2011.

[3] A. Atasu, Ö. Özdemir, and L.N. Van Wassenhove, Stakeholder perspectives under take-back legislation, Prod Oper Manage 22 (2013), 382-396.

[4] A. Atasu, M. Sarvary, and L.N. Van Wassenhove, Efficient take-back legislation, Prod Oper Manage 18 (2009), 243-258.

[5] R.B. Belzer and A.L Nichols, Economic incentives to encourage hazardous waste minimization and safe disposal, 1988, Available at: http://yosemite.epa.gov/ee/epa/eerm.nsf /vwAN/EE-0173.pdf/\$file/EE-0173.pdf, last accessed May, 2013.

[6] Boeing, Regulatory oversight, 2014, Available at: http://www.boeing.com/boeing/aboutus/environment/santa_ susana/oversight.page, last accessed July, 2014.

[7] British Columbia Government, Predictive ecosystem mapping, 2012, Ministry of Environment, Lands and Parks, British Columbia, Canada, Available at: www.for.gov.bc.ca/hre/temalt/docs/PEMschedA.doc, last accessed February, 2013.

[8] P. Brucker, A. Drexl, R. Möhring, K. Neumann, and E. Pesch, Resource-constrained project scheduling: Notation, classification, models, and methods, Eur J Oper Res 112 (1999), 3-41.

[9] BSI, Sustainable film, 2014, Available at: http://shop.bsigroup. com/Browse-By-Subject/Environmental-Management-andSustainability/Sustainability/Sustainable-film-with-BS8909/, last accessed July, 2014.

[10] P. Calcott and M. Walls, Can downstream waste disposal policies encourage upstream design for environment?, Am Econ Rev 90 (2000), 233-237.
[11] CALGreen, A guide to the California green building standards code, 2012, Available at: http://www. documents.dgs.ca.gov/bsc/CALGreen/MasterCALGreenNonResGuide2010_2012Suppl-3rdEd_1-12.pdf, last accessed May, 2013.

[12] California Building Standards Commission, Guide to the (non-residential) California green building standards code, Technical report, 2010, Available at: http://www.documents.dgs.ca.gov/bsc/CALGreen/MasterCALGreen-Non-Res-Guide2010-sec-ed-final-3-1-11.pdf, last accessed February, 2013.

[13] CalRecycle, California green building standards code, frequently asked questions, 2013, Available at: http:// www.calrecycle.ca.gov/LGCentral/Library/canddmodel/ instruction/faq.htm, last accessed May, 2013.

[14] R. Carmona and J. Hinz, Risk-neutral models for emission allowance prices and option valuation, Manage Sci 57 (2011), 1453-1468.

[15] W. Chapple, C.J.M. Paul, and R. Harris, Manufacturing and corporate environmental responsibility: Cost implications of voluntary waste minimisation, Struct Change Econ Dyn 16 (2005), 347-373.

[16] P. Chen, P. Narayan, L.N. Van Wassenhove, and H. Ghaziri. The WEEE challenge, INSEAD Case Study, 2004, ECCH Case No. 304-624-1.

[17] City of Seattle, Construction Waste Management, 2013, Available at: http://www.seattle.gov/dpd/cms/groups/pan/ @ pan/@ sustainableblding/documents/web_informational/ dpdp016431.pdf, last accessed February, 2013.

[18] E.H. Clarke, Multipart pricing of public goods, Public Choice 11 (1971), 17-33.

[19] B. Colson, P. Marcotte, and G. Savard, An overview of bilevel optimization, Ann Oper Res 153 (2007), 235256.

[20] K. Conrad, Incentive mechanisms for environmental protection under asymmetric information: A case study, Appl Econ 23 (1991), 871-880.

[21] K. Conrad and J. Wang, On the design of incentive mechanisms in environmental policy, Environ Resour Econ 3 (1993), 245-262.

[22] C.J. Corbett and S. Muthulingam, Adoption of voluntary environmental standards: The role of signaling and intrinsic benefits in the diffusion of the LEED green building standards, 2007, Available at SSRN 1009294.

[23] P. Dasgupta, P. Hammond, and E. Maskin, On imperfect information and optimal pollution control, Rev Econ Stud 47 (1980), 857-860.

[24] E.W. Davis and G.E. Heidorn, An algorithm for optimal project scheduling under multiple resource constraints, Manage Sci 17 (1971), 803-816.

[25] E. Demeulemeester, M. Vanhoucke, and W. Herroelen, RanGen: A random network generator for activity-on-thenode-networks, J Scheduling 6 (2003), 17-38.

[26] S. Dempe, Foundations of bilevel programming, Kluwer Academic Publishers, Dordrecht, 2002.

[27] I. Dobos and K. Richter, An extended production/recycling model with stationary demand and return rates, Int J Prod Econ 90 (2004), 311-323.

[28] EPA, Spotlight on waste prevention: EPA's program to reduce solid waste at the source, 1995, Available at: http://www.epa.gov/epawaste/conserve/pubs/spotlght.pdf, last accessed May, 2013. 
[29] EPA, Regulatory information by topic, 2014, Available at: http://www2.epa.gov/regulatory-information-topic, Last accessed July, 2014.

[30] GreenCodePro, Reducing the cost of CALGreen implementation, 2011, Available at: http://greencodepro.com/reducingthe-costs-of-calgreen-implementation, last accessed February, 2013.

[31] GreeningFilm, BS 8909: Guidance notes-specification for a sustainability management system for film, 2012, Available at: http://www.greeningfilm.com/wpcontent/uploads/2012/10/BS-8909-Guidance-Notesfinal3.pdf, last accessed July, 2014.

[32] T. Groves, Incentives in teams, Econometrica 41 (1973), 617-631.

[33] C. Hendrickson, Project management for construction, 2.2 ed., Wiley, Hoboken, NJ, 2008, Available at: http://pmbook.ce.cmu.edu/, last accessed July, 2013.

[34] W. Herroelen, B. De Reyck, and E. Demeulemeester, Resource-constrained project scheduling: A survey of recent developments, Comput Oper Res 25 (1998), 279-302.

[35] C.G. Hill, CALGreen. It's finally here. Now what? 2013, Available at: http://constructionlawva.com/calgreen-itsfinally-here-now/, last accessed February, 2013.

[36] HKEPD, Construction waste disposal charging scheme, 2011, Hong Kong Environmental Protection Department, Available at: http://www.epd.gov.hk/epd/misc/cdm/scheme.htm, last accessed February, 2013.

[37] HM Government, Strategy for sustainable construction, 2008, California Code of Regulations, Title 24, Part 11, Available at: http://www.bis.gov.uk/files/file46535.pdf, last accessed February, 2013.

[38] HomeWyse, Cost to remove construction debris, 2013, Available at: http://www.homewyse.com/services/cost_ to_remove_construction_debris.html, last accessed July, 2013.

[39] How Do I Manage My Remediation Waste? 2013. Available at: http://www.epa.state.il.us/small-business/remedial-waste/, last accessed May, 2013.

[40] IRN, The cost of recycling vs disposal of construction and demolition wastes, 2013, The Instutition Recycling Network, Available at: http://www.wastemiser.com/ costcomparisonchart.pdf, last accessed July, 2013.

[41] Ö. İşlegen and S. Reichelstein, Carbon capture by fossil fuel power plants: An economic analysis, Manage Sci 57 (2011), 21-39.

[42] A. Jaafari, Management of risks, uncertainties, and opportunities on projects: Time for a fundamental shift, Int J Proj Manage 19 (2001), 89-101.

[43] B. Jacobs and R. Subramanian, Sharing responsibility for product recovery across the supply chain, Prod Oper Manage 21 (2011), 85-100.

[44] A. Khan, Project scope management, Cost Eng 48 (2006), 12-16.

[45] K. Klingebiel, Y. Gavrylenko, and A. Wagenitz, Adoption of simulation techniques for mastering logistic complexity of major construction and engineering projects, in: Proceedings, 24th European Conference on Modelling and Simulation, Kuala Lumpur, 2010.

[46] R. Kolisch, A. Sprecher, and A. Drexl, Characterization and generation of a general class of resource-constrained project scheduling problems, Manage Sci 41 (1995), 1693-1703.

[47] E. Kwerel, To tell the truth: Imperfect information and optimal pollution control, Rev Econ Stud 44 (1977), 595-601.
[48] J. Laquatra and M.R. Pierce, Waste management at the construction site, Cornell cooperative extension, 2002, Available at: http://www.human.cornell.edu/dea/outreach/ upload/Waste_Management-booklet.pdf, Last accessed July, 2014.

[49] M.D. Levi and B.R. Nault, Converting technology to mitigate environmental damage, Manage Sci 50 (2004), 1015-1030.

[50] R. Lifset, Take it back: Extended producer responsibility as a form of incentive-based environmental policy, J Resour Manage Technol 21 (1993), 163-175.

[51] C. Liu, A look behind the scenes: How green is Hollywood? 2008, Available at: https://twp.duke.edu/uploads/ assets/Liu.pdf, last accessed July, 2014.

[52] NCEE, The United States experience with economic incentives for protecting the environment, Technical report, 2001, National Center of Environmental Economics EPA-240-R-01001 .

[53] A. Ovchinnikov, D. Krass, and T. Nedorezov, Environmental taxes and the choice of green technology, 2013, Production and Operations Management, 22(5), 1035-1055.

[54] K. Palmer and M. Walls, Optimal policies for solid waste disposal: Taxes, subsidies, and standards, J Public Econ 65 (1997), 193-205.

[55] E.L. Plambeck and Q. Wang, Effects of e-waste regulation on new product introduction, Manage Sci 5 (2010), 333-347.

[56] PMI, Should you be teaching project management? Project Management Institute, Newton Square, 2013.

[57] Pollution Prevention Resource Center PPRC, Ship building and repair: Reasons for change, 2008, Available at: http://www.epa.gov/ttn/atw/188polls.html, last accessed July, 2014.

[58] PRWeb, Reducing the costs of CALGreen implementation by using green code pro, 2013, Available at: http://www.prweb.com/releases/2011/4/prweb8327268.htm, last accessed February, 2013.

[59] PZC, The successful virtual team-motivating, engaging and managing a geographically diverse project teams, 2013, Project Zone Congress, Available at: http://2013.projectzonecongress.com/session/successfulvirtual-team-motivating-engaging-and-managinggeographically-diverse-project-team, last accessed July, 2014.

[60] S.K. Sears, G.A. Sears, and R. Clough, Construction project management, Wiley, Hoboken, NJ, 2000.

[61] K. Segerson and N. Li, Voluntary approaches to environmental protection, Edward Elgar, Cheltenham, UK, 1999, pp. 273-306.

[62] R.N. Stavins, Market-based environmental policies, Resources for the Future, Discussion Paper, RFF 98-26, 2000.

[63] R. Subramanian, S. Gupta, and B. Talbot, Product design and supply chain coordination under extended producer responsibility, Prod Oper Manage 18 (2009), 259-277.

[64] Sustainable Sources, Construction waste recycling, 2013, Available at: http://constructionwaste.sustainablesources. com/, last accessed February, 2013.

[65] SWMCB, On-site grinding and beneficial reuse of construction waste, 2003, Solid waste management coordinating board, Available at: http://www.swmcb.org/sites/default/ files/files/DraftFinalReport.pdf, last accessed July, 2013.

[66] F.B. Talbot, Resource-constrained project scheduling with time-resource tradeoffs: The nonpreemptive case, Manage Sci 28 (1982), 1197-1210. 
[67] The District of Columbia, DC Green Building Act Information, 2013, Available at: http://www.dc. gov/DC/DSLBD/Business+Resources/Green-Sustainability+ Business+Resources/DC+Green+Building+Act+Information, last accessed May, 2013.

[68] The District of Columbia, Sustainable DC Plan, 2013, Available at: http://sustainable.dc.gov/finalplan, last accessed May, 2013.

[69] F. Toyasaki, T. Boyaci, and V. Verter, An analysis of monopolistic and competitive take-back schemes for WEEE recycling, Prod Oper Manage 20 (2010), 805-823.

[70] W. Unold and T. Requate, Pollution control by options trading, Econ Lett 73 (2001), 353-358.

[71] URS, Construction waste, 2013, Available at: http://www.devon.gov.uk/dcc3242_150.pdf, last accessed July, 2013.

[72] U.S. Congress, Office of Technology Assessment, Environmental policy tools: A user's guide, OTA-ENV-634, U.S. Government Printing Office, Washington, DC, 1995, Available at: https://www.princeton.edu/ ota/disk1/1995/9517/9517.PDF, Last accessed July, 2014.

[73] USGBC, LEED for new construction and major renovations, 2005. U.S. Green Building Council, Available at: http://www.usgbc.org/ShowFile.aspx? DocumentID=1095, last accessed February, 2013.

[74] W. Vickrey, Counterspeculation, auctions, and competitive sealed tenders, J Finance 16 (1961), 8-37.
[75] B. Vila, Your home's construction schedule, 2013, Available at: http://www.bobvila.com/articles/24-yourhome-s-construction-schedule/pages/1, last accessed July, 2013.

[76] M. Walls and J. Hanson, Distributional aspects of an environmental tax shift: The case of motor vehicle emissions taxes, Natl Tax J 52 (1999), 53-66.

[77] M. Walls and K. Palmer, Upstream pollution, downstream waste disposal, and the design of comprehensive environmental policies?, J Environ Econ Manage 41 (2001), 94-108.

[78] C. Wohlin and C. Vrana, A quality constraint model to be used during the test phase of the software life cycle, in: Proceedings, 6th International Conference on Software Engineering for Telecommunication Switching Systems, 1986, pp. 136141.

[79] WRAP, Actions to reduce waste in construction projects and minor works, 2013, Available at: http://www.wrap.org.uk/sites/files/wrap, last accessed May, 2013.

[80] WWF, Living planet report, 2010, Available at: http://wwf. panda.org/about_our_earth/all_publications/living_planet_ report, last accessed February, 2013.

[81] R.K. Wysocki, Effective project management, 5th ed., Wiley, Hoboken, NJ, 2009.

[82] R. Zuidwijk and H. Krikke, Strategic response to EEE returns: Product eco-design or new recovery process?, Eur J Oper Res 191 (2007), 1206-1222. 